\title{
Digital spatial profiling of coronary plaques from persons living with HIV reveals high levels of STING and CD163 in macrophage enriched regions
}

Celestine N. Wanjalla ${ }^{1,8}$, Liang Guo ${ }^{2}$, Daniela T. Fuller ${ }^{2}$, Mona Mashayekhi ${ }^{3}$, Samuel Bailin ${ }^{1}$, Curtis L. Gabriel ${ }^{4}$, Tecla Temu ${ }^{5}$, Jingjing Gong ${ }^{6}$, Yan Liang ${ }^{6}$, Renu Virmani ${ }^{2}$, Aloke V. Finn ${ }^{2}$, Spyros A. Kalams ${ }^{1,9}$, Simon A. Mallal ${ }^{1,7,8}$, Jonathan J. Miner ${ }^{9}$, Joshua A. Beckman ${ }^{10}$, John R. Koethe $e^{1,8,12}$

1 Division of Infectious Diseases, Vanderbilt University Medical Center, Nashville, TN, USA

2 CVPath Institute, Gaithersburg, MD, USA

3 Division of Diabetes, Endocrinology and Metabolism, Vanderbilt University Medical Center, Nashville, TN, USA

4 Division of Gastroenterology, Vanderbilt University Medical Center, Nashville, TN, USA

5 Departments of Global Health, University of Washington, Seattle, WA, USA

6 NanoString Technologies Inc, Seattle, WA, USA

7 Vanderbilt Technologies for Advanced Genomics, Vanderbilt University Medical Center, Nashville, TN, USA

8 Tennessee Center for AIDS Research, Vanderbilt University Medical Center, Nashville, TN, USA

9 Washington University, Department of Medicine, Pathology and Immunology, and Molecular Microbiology, Division of Infectious Diseases, St. Louis, MS, USA

10 Division of Cardiovascular Medicine, Vanderbilt University Medical Center, Nashville, TN, USA

${ }^{11}$ Veterans Affairs Tennessee Valley Healthcare System, Nashville, TN

† Corresponding authors: Celestine N. Wanjalla, MD, PhD; Division of Infectious Diseases, Vanderbilt University Medical Center, A-2200 MCN, 1161 21st Ave S., Nashville, TN, 372322582. (615) 322-2035 (o), (615) 343-6160 (f), celestine.wanjalla@vumc.org. 


\section{Graphical Abstract}

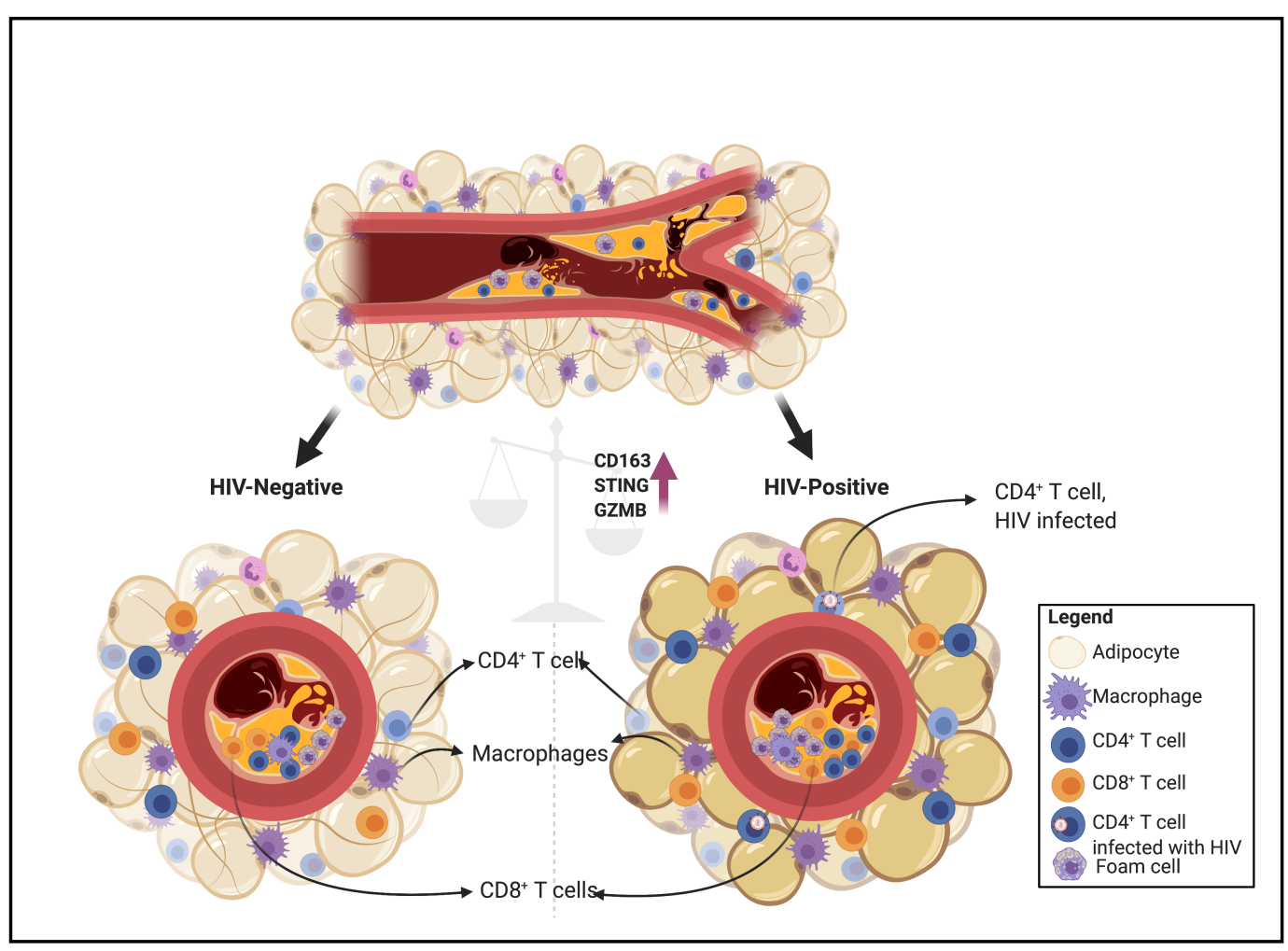

\section{Highlights}

1. Immunohistochemical and fluorescent stains combined with GeoMx ${ }^{\circledR}$ digital spatial profiling allowed for deep characterization of immune cells within intact coronary plaques and perivascular adipose tissue

2. Coronary plaques from HIV-positive persons had higher proportion of CD163 ${ }^{+}$immune cells compared to HIV-negative persons

3. Differential protein expression of immune-rich regions of interest within intact $5 \mu \mathrm{m}$ sections of coronary plaques revealed higher levels of stimulator of interferon gamma (STING) in HIV-positive persons 


\section{Abstract Background}

Chronic innate and adaptive immune activation may contribute to high prevalence of cardiovascular disease in persons living with HIV (PLWH).

\section{Methods}

We assessed coronary plaques from deceased PLWH $(n=6)$ and HIV-negative $(n=6)$ persons matched by age and gender. Formalin-fixed, paraffin-embedded $5 \mu \mathrm{m}$ thick sections were processed using Movat, hematoxylin and eosin, immunohistochemical and immunofluorescence stains. Immune cell populations were measured using surface antibodies, and immune-related protein expression from macrophage rich, T-cell rich and perivascular adipose tissue regions using $\mathrm{GeoMx}{ }^{\circledR}$ digital spatial profiling.

\section{Results}

Coronary plaques from PLWH and HIV-negative persons had similar plaque area and percent stenosis. Percent $\mathrm{CD}_{163^{+}}$cells as measured by immunohistochemical staining was significantly higher in PLWH, median 0.29\% (IQR 0.11-0.90) vs. 0.01\% (IQR 0.0013-0.11) in HIV-negative plaque, $p=0.02$ (Figure 1A). Other surface markers of innate cells (CD68 $\left.{ }^{+}, p=0.18\right)$, adaptive immune cells $\left(\mathrm{CD}^{+}, \mathrm{p}=0.39 ; \mathrm{CD}^{+}, \mathrm{p}=0.09 ; \mathrm{CD}^{+}, \mathrm{p}=0.18\right)$ and immune trafficking markers $\left(\mathrm{CX} 3 \mathrm{CR} 1^{+}, \mathrm{p}=0.09\right)$ within the coronary plaque trended higher in HIV-positive plaques but did not reach statistical significance. GeoMx ${ }^{\circledR}$ digital spatial profiling showed higher differential protein expression of CD163 (scavenger receptor for hemoglobin-haptoglobin complex), stimulator of interferon gamma (STING, a cytosolic DNA sensor), CD25 and granzyme-B in the HIV-positive compared to HIV-negative, $p<0.05$ (Figure 1B).

\section{Conclusions}


Increased inflammation within the coronary plaques of PLWH is characterized by more innate and adaptive immune cells. Higher STING expression in PLWH suggests that immune response to viral antigens within the plaque might be a driver above other stimulants. STING inhibitors are available and could be investigated as a future therapeutic target in $\mathrm{PWH}$ if these results are replicated with a larger number of plaques.

Key words: Atherosclerosis, cardiovascular disease, HIV, stimulator of interferon gamma, CX3CR1, cytomegalovirus, inflammation 


\section{Introduction}

2 Persons living with human immune deficiency virus (PLWH) have a greater prevalence of

3 cardiovascular disease (CVD) compared to HIV-negative persons, which is not explained by

4 differences in traditional risk factors and persists despite suppression of plasma viremia on

5 antiretroviral therapy (ART). ${ }^{1-5}$ Chronic inflammation due to HIV-infection and other viral

6 pathogens such as cytomegalovirus (CMV) and hepatitis $\mathrm{C}$ virus, have been linked to

7 accelerated atherosclerosis ${ }^{6,7}$ and may in part explain this increased risk. Aortic and carotid

8 artery inflammation measured by 18F-fluorodeoxyglucose positron emission tomography (FDG-

9 PET) imaging, ${ }^{14,15}$ showed greater tracer uptake in PLWH and was associated with higher

10 plasma hsCRP, IL-6, CX3CR $1^{+}$monocytes, and potentially CX3CR $1^{+} \mathrm{CD} 4{ }^{+} \mathrm{T}$ cells. ${ }^{14} \mathrm{In}$

general, PLWH on ART have higher levels of inflammation compared to HIV-negative persons.

${ }^{9}$ Higher levels of circulating interleukin-6 (IL-6), high sensitivity c-reactive protein (hsCRP) and

with low or undetectable plasma viremia in the absence of ART, notably also showed higher

17 not the driver of vascular disease..$^{13}$

Different circulating immune cell subsets have been associated with CVD in the general population and PLWH, though results have been conflicting. CD27- CD28- CD45RO ${ }^{+} \mathrm{CD}^{+} \mathrm{T}$

21 cells, for example, were associated with increased mortality from coronary heart disease. ${ }^{16}$ In

22 contrast, a large analysis combining participants in the Multi-Ethnic Study of Atherosclerosis

23 (MESA) and the Cardiovascular Health Study (CHS) found that circulating lymphocytes (CD4 ${ }^{+}$,

$\left.24 \mathrm{CD}^{+}, \mathrm{CD}^{+} 9^{+}\right)$and monocytes $\left(\mathrm{CD} 14^{+}\right)$were not associated with future myocardial infarction in

25 otherwise healthy adults ${ }^{17}$. Among PLWH, lower CD4 ${ }^{+}$T cell counts have been linked with

26 higher rates of non-AIDS diseases, including CVD. ${ }^{18} \mathrm{CD}^{+} \mathrm{T}$ cell counts less than 200 
27 cells $/ \mathrm{mm}^{3}$ were also associated with greater arterial stiffness ${ }^{19}$ and carotid plaque (IMT > $1.5 \mathrm{~mm}) .{ }^{20}$ In other studies and in contrast, higher absolute CD4 ${ }^{+} \mathrm{T}$ cell counts post-ART at the time of CVD assessment have also been associated with cardiovascular aging in $\mathrm{PLWH} .{ }^{21} \mathrm{~A}$ potential explanation of this paradox is the expansion of a subset of cytotoxic CMV-specific

$31 \mathrm{CD}^{+} \mathrm{T}$ cells in the presence of ART which are highly inflammatory and atherogenic. The

32 majority of PLWH are co-infected with CMV and have inflated $\mathrm{CD}^{+}$and $\mathrm{CD}^{+} \mathrm{T}^{\mathrm{T}}$ cells dedicated

33 to controlling CMV replication. ${ }^{22,23}$ A higher percentage of CMV-specific CD8 ${ }^{+} \mathrm{T}$ cells in PLWH

34 is associated with increased carotid intima-media thickness, ${ }^{24}$ while higher anti-CMV IgG titers

35 are associated with subclinical carotid artery disease and increased mortality from coronary heart disease. ${ }^{16,25}$

Although inflammation is thought to play an important role in the development of an atheroma, and therapeutic targets including antiviral therapies or immune therapies have been proposed, to our knowledge there has been no research on the immune landscape of arterial plaques in

41 persons with HIV. A comparison of plaques from PLWH vs. HIV-negative persons may delineate

42 inflammatory pathways contributing to a higher burden of CVD. We previously described the C-

43 G-C ${ }^{+} \mathrm{CD}^{+} \mathrm{T}$ cells co-expressing CX3CR1 and CD57 in HIV-positive diabetics, and found that

44 these cells are predominantly $\mathrm{T}_{\text {EMRA }}$ cells and overlap with CD28- CD4 ${ }^{+} \mathrm{T}$ cells that have been

45 described in aging individuals ${ }^{26}$. Further, a recent publication using single cells isolated from

46 carotid plaque samples of HIV-negative individuals, showed expression of CX3CL1 in nascent

47 plaque and $\mathrm{CX} 3 \mathrm{CR} 1^{+} \mathrm{CD} 57^{+} \mathrm{CD} 4^{+} \mathrm{T}$ cells within the plaque by flow cytometry. ${ }^{27}$ They did not

48 include plaque from HIV-positive samples which we address in this study.

50 Understanding the role of inflammation in atherosclerosis requires definitive evidence using in51 depth analysis of immune cells within plaque tissue ${ }^{28}$. This has not been done in PLWH and 52 until now, we were limited in our ability to investigate immune subsets within vulnerable human 
53 plaque tissue due to high levels of necrosis that affected the integrity of surrounding tissue and

54 immune cell yield ${ }^{29-33}$. In this paper, we investigated immune cells within coronary plaque tissue

55 and surrounding adventitia using $\mathrm{GeoMX}{ }^{\circledR}$ digital spatial profiling which allowed us to pick

56 regions within the plaque and compare surface and intracellular protein expression. Plaques are

57 heterogenous and understanding the immune drivers of atherogenesis is enhanced by the new

58 technologies that allow us to select regions within the plaque for detailed analysis.

60 As metabolic disease and CVD are co-travelers, we hypothesized that C-G-C CD4 ${ }^{+}$T cells

61 which express CX3CR1 could traffic to inflamed endothelium and contribute to CVD progression

62 in PLWH. C-G-C CD4 ${ }^{+}$T are cytotoxic and more commonly anti-viral. We obtained coronary

63 plaques from twelve deceased individuals with $(n=6)$ and without HIV $(n=6)$ of similar age and

64 sex distribution. The coronary plaques were staged and evaluated for immune cells using

65 immunohistochemistry staining. We found that plaques from PLWH had higher proportions of

66 immune cells per area, with significantly more $\mathrm{CD}_{163^{+}}$cells. Most importantly, using GeoMX ${ }^{\circledR}$

67 digital spatial profiling, we found a significantly higher expression of stimulator of interferon

68 gamma (STING), CD163, and several immune proteins consistent with a cytotoxic response in

69 the HIV-positive coronary plaque.

\section{Methods and materials}

\section{Human samples}

73 This study used deidentified human coronary plaque samples/ autopsy specimens approved for

74 exempt review by the institutional review boards of CVPath and Vanderbilt University Medical

75 Center (IRB\# 200148). Slides containing major epicardial coronary arteries sectioned at 3-4mm

76 intervals from six HIV-positive and six HIV-negative persons who died of sudden cardiac death

77 were obtained from the CVPath Institute (Gaithersburg, MD) (Supplementary Table 1). CVPath

78 Institute maintains curated biorepository of coronary artery beds from over 7000 autopsy hearts 
79 from the Office of the Chief Medical Examiner of the State of Maryland (OCME-MD) collected

80 between 2005 and 2019, for providing cardiac consultation. Each heart is evaluated by a

81 cardiac pathologist for staging and the cause of death, if known, is recorded along with de-

82 identified demographic information including age, gender, and race. Each specimen is fixed in

$8310 \%$ formalin and regions of interest are decalcified before processing. The arteries with

84 coronary plaques are fixed and serial sections embedded in paraffin. Sections are cut at 5-6 $\mu \mathrm{m}$

85 and mounted on charged slides ${ }^{35}$.

\section{Immunohistochemical staining}

88 FFPE sections were stained using Movat pentachrome and hematoxylin and eosin stains

89 (H\&E). We selected immune markers to define innate and adaptive Immune cells present in the

90 plaques. These were identified by immunohistochemical staining (IHC) with antibodies against $\mathrm{T}$

91 cells: CD3 (Roche Cat \# 790-4341, pre-diluted), CD4 (Roche, Cat\# 790-4423, pre-diluted), CD8;

92 macrophages: CD68 (Roche Cat\# 790-2931, pre-diluted), CD163 (Leica Cat\# NCL-L-CD163,

93 antibody 1:50), vascular cell adhesion molecule 1 (VCAM-1) (Abcam ab134047, 1:500, diluted)

94 and an endothelial homing chemokine receptor, CX3CR1 (Abcam ab8021, 1:1000 dilution),

95 DISCOVERY OmniMap anti-Ms HRP cat \# 760-4310 or anti-Rb HRP cat \# 760-4311 and

96 developed by the NovaRed kit (Vector Laboratories). The images were captured by Axio

97 Scan.Z1 (Zeiss, Germany) using a 20X objective. IHC staining was quantified in segments with

98 the most severe stenosis using the area quantification module on the HALO image analysis

99 platform (Indica Labs, Corrales, NM) as previously published. ${ }^{35,36}$

100

101 Digital Spatial profiling of protein expression

102 Expression of multiple immune-related proteins was measured on $5 \mu \mathrm{m}$ thickness formalin-fixed

103 paraffin-embedded (FFPE) tissue sections from the coronary plaques of two male HIV-positive 
and HIV-negative with the highest degree of immune cell infiltration. FFPE sections were treated with citrate buffer $(\mathrm{pH} 6)$ for antigen retrieval. They were bathed in a multiplexed cocktail of

106 primary antibodies with photocleavable DNA-indexing oligos (GeoMX ${ }^{\circledR}$ Immune profile core,

107 Immune Cell typing, Immune Activation Status, IO Drug Target and Pan Tumor modules),

108 fluorescent anti-CD3 (magenta, Cat.\# UM500048 ), anti-CD8 (green, Cat.\# 14-0008-82), anti-

109 CD68 (yellow, Cat.\# sc-20060) and SYTO 83 nuclear staining (Cat.\# S11364). Fluorescence

110 microscopy on the GeoMX ${ }^{\circledR}$ platform was used to image the slides. Twelve regions of

111 interest/areas of interest (ROIs/AOIs) from each were processed using the NanoString's

112 GeoMX ${ }^{\circledR}$ digital spatial profiling platform (https://www.nanostring.com/scientific-

113 content/technology-overview/digital-spatial-profiling-technology). Images of stained sections

114 were captured at 20X magnification. ROIs/AOIs for molecular profiling were selected as

115 geometric shapes in macrophage-abundant, T-cell abundant and adipose tissue sections. Per

116 protocol, protein staining was repeated twice to verify the results. AOls were exposed to

117 ultraviolet light $(365 \mathrm{~nm})$ to release the indexed oligos/barcodes for collection. Oligos were

118 captured from the AOI by microcapillaries and dispensed into 96-well plates. Following

119 collections from all AOls, the oligos (hybridized to unique four-color, six-spot optical indexing

120 barcodes) were quantified on the nCounter analysis platform. Data were normalized to area;

121 signal-to-noise ratios (SNR) were calculated using isotype controls. Proteins with SNR less than

1222 were not included in differential expression analysis. Data were visualized by unsupervised

123 hierarchical clustering. Differential gene expression was analyzed by unpaired $t$-test with

124 Benjamini Hochberg $(\mathrm{BH})$ correction.

125

\section{Statistical analysis}

127 Differential expression of proteins in coronary plaques and correlation plots of protein 128 expression were analyzed using t-test on the GeoMx ${ }^{\circledR}$ software platform with Benjamini

129 Hochberg correction for multiple comparisons, where applicable. Statistical differences in 
130 immune cells within coronary plaques of HIV-positive and HIV-negative persons were calculated

131 using GraphPad Prism 8 and R v.3.6.1.

133 Results

134 Demographics of HIV-negative and HIV-positive persons

135 We obtained coronary plaques from six HIV-positive (median age 50) and six HIV-negative

136 deceased persons (median age 52) (Supplementary Table 1). Half of each group was female.

137 There were more Caucasians in the HIV-negative group (5/6) compared to the HIV-positive

138 group (1/6). The coronary plaque lesions consisted of early and late atheroma (Supplementary

139 Table 1). The cardiac death categories, as applicable, are also provided for reference in the 140 table.

Coronary plaque morphology and immune cell constituents in HIV-positive and HIVnegative persons

144 We first compared the coronary plaque histology between HIV-positive and HIV-negative 145 persons. Movat and H\&E stains were used to define the coronary plaque constituents; three 146 representative images are shown (Figure 1A). There was no significant difference in plaque 147 area (median $4.74 \mathrm{E}^{6} \mu \mathrm{m}^{2}\left[2.78 \mathrm{E}^{6}-8.00 \mathrm{E}^{6}\right]$ in HIV-negative vs. $7.05 \mathrm{E}^{6} \mu \mathrm{m}^{2}\left[5.59 \mathrm{E}^{6}-8.81 \mathrm{E}^{6}\right]$ in 148 HIV-positive, $p=0.31$ ) or percent stenosis (median 66\% [54 - 72] in HIV-negative vs. 50\% [41149 62] in HIV-positive, $p=0.13$ ) (Figure 1B). Using IHC, we quantified cells of the innate and 150 adaptive immune system. CD68 is a surface marker expressed on monocytes and 151 macrophages; CD3/CD4/CD8 are markers expressed on T cells and vascular cell adhesion 152 molecule 1 (VCAM-1) and CX3CR1) are markers associated with trafficking to inflamed 153 endothelium (Figure 2A). We found no difference in the percentage of $\mathrm{CD}^{+} 8^{+}$cells between 154 HIV-negative (median 0.38\% per $\mu \mathrm{m}^{2}[0.13,1.11]$ ) and HIV-positive $(1.58 \%$ [0.28, 2.94]) 
coronary plaques, $p=0.18$. Similarly, the percentage of T cells was not different between HIVnegative and HIV-positive coronary plaque: CD3 (median $0.07 \%$ per $\mu \mathrm{m}^{2}[0.03,0.23]$ vs. $0.2 \%$ per $\left.\mu \mathrm{m}^{2}[0.11,0.34], p=0.39\right]$ ); CD4 (median $0.001 \%$ per $\mu \mathrm{m}^{2}[0.0006,0.05]$ vs. $0.1 \%$ per $\mu \mathrm{m}^{2}$ $[0.007,0.26], p=0.09]$ ) or CD8 T cells (median $0.05 \%$ per $\mu \mathrm{m}^{2}[0.004,0.17]$ vs. $0.17 \%$ per $\mu \mathrm{m}^{2}$ $[0.08,0.28], p=0.18])$. Similar trends were seen in the markers associated with trafficking of cells

160 to inflamed endothelium VCAM-1 (median $0.008 \%$ per $\mu \mathrm{m}^{2}[0.002,0.03]$ vs. $0.05 \%$ per $\mu \mathrm{m}^{2}$

$161[0.009,0.2], p=0.24]$ ) and CX3CR1 (median 0.1\% per $\mu \mathrm{m}^{2}[0.08,0.9]$ vs. $0.8 \%$ per $\mu \mathrm{m}^{2}[0.6$,

162 1.3], $p=0.09])$. In aggregate, there appeared to be a trend towards more immune cells in

163 coronary plaques from HIV-positive individuals (Figure 2B). Similarly, we obtained high

164 magnification images of perivascular adipose tissue adjacent to the coronary plaques that

165 showed the presence of innate and adaptive immune cells (Supplementary Figure 1)

Membrane bound CD163 is a scavenger receptor of hemoglobin-haptoglobin complexes that is expressed exclusively on macrophages ${ }^{37}$. This receptor in humans can be cleaved by the inflammation-inducible enzyme TNF- $\alpha$ converting enzyme (TACE) to generate soluble CD163

170 that has been shown to be higher in the peripheral blood of PLWH. ${ }^{38}$ Previous studies

171 comparing sCD163 expression found higher levels in HIV+CMV+ compared to HIV+CMV-

172 persons $^{42}$. CD $163^{+}$macrophages have been associated with a high level of HIF1 $\alpha$ expression

173 and plaque progression due to increased plaque angiogenesis and plaque vulnerability. We

174 found that $\mathrm{CD}_{163}{ }^{+}$cells were more prevalent in the HIV-positive (median $0.29 \%$ per $\mu \mathrm{m}^{2}[0.11$,

175 1.45]) versus HIV-negative (median 0.01\%per $\mu \mathrm{m}^{2}[0.001,0.11]$ ), $p=0.02$ ) (Figure 2). Although

176 vascular adhesion molecule-1 $\left(\mathrm{VCAM}^{+} \mathbf{1}^{+}\right)$was higher in HIV-positive (median 0.05\% per $\mu \mathrm{m}^{2}$

$177[0.009,0.20]$ ) versus HIV-negative (median $0.008 \%$ per $\left.\mu \mathrm{m}^{2}[0.002,0.03]\right), p=0.24$ ), this

178 difference was not statistically different in this small sample. Taken together, coronary plaque 179 samples from HIV-positive and HIV-negative deceased persons had a median plaque area and 
stenosis that was similar. However, there was a trend towards higher percentages of immune cells in HIV-positive samples, with significantly higher CD163+ cells and a trend towards higher CX3CR $1^{+}$cells.

Innate and adaptive immune cells did not correlate with plaque stenosis in HIV-positive

186 Immune cell enrichment in coronary plaques is non-stochastic and is a harbinger of

187 atherosclerosis progression. Monocytes are recruited early after endothelial injury and are

188 stimulated to become macrophages in the sub-endothelium. Using correlation matrices, we 189 looked to see if there were relationships between plaque area, plaque stenosis and plaque 190 resident immune subsets. Spearman's rank correlation analysis agnostic to HIV-status, showed 191 that $\mathrm{CD} 8^{+}$cells were positively correlated with $\mathrm{CD}_{163^{+}}(\mathrm{rho}=0.79, p<0.01), \mathrm{CD}^{+}(\mathrm{rho}=0.69$, $p<0.05), \mathrm{CD}^{+}($rho $=0.74, p<0.01)$, and $\mathrm{CX} 3 \mathrm{CR} 1^{+}($rho $=0.71, p<0.05)$ cells. $\mathrm{CD}^{+}($rho $=$ $0.52, p=0.09)$ and $\mathrm{VCAM}-1^{+}($rho $=0.42, p=0.18)$ were not significant (Figure 3A). We observed that $\mathrm{CX} 3 \mathrm{CR} 1^{+}$cells were positively correlated with $\mathrm{CD} 163^{+}(r=0.88, p<0.001), \mathrm{CD}^{+}$ $(r=0.80, p<0.01), \mathrm{CD}^{+}(\mathrm{r}=0.76, p<0.01), \mathrm{CD}^{+}(\mathrm{r}=0.80, p<0.01)$, and VCAM-1 $(r=0.67, p<$ correlated with $\mathrm{CD}_{163^{+}}, \mathrm{CD}^{+}, \mathrm{CD}^{+}$, and $\mathrm{CD} 8^{+}$cells in HIV-negative (Figure 3B,D). On the contrary, percent stenosis was not correlated with all immune subsets in HIV-positive individuals (Figure 3C,D).

\section{Coronary plaque heterogeneity in HIV-positive and HIV-negative persons}

202 Coronary plaque FFPE sections from two individuals (one HIV-positive and one HIV-negative)

203 were selected and matched on age, morphology, sex and percent of immune cells as seen by 204 IHC $\left(\mathrm{CD} 68^{+}\right.$cells, 2.7\% HIV-positive and 2.3\% in HIV-negative; CX3CR1+, 1.4\% HIV-positive 205 and $2.0 \%$ in HIV-negative). CD163 and VCAM-1 positivity was higher in the HIV-positive 
samples (IHC stains) compared to the HIV-negative samples (Supplementary Table 2).

207 Representative sections from each of these individuals were stained with fluorescently tagged

208 antibodies (CD3, CD8, CD68 and DAPI) and sequential areas of interest (AOI) from each

209 individual was selected (Figure 4A). Twelve regions were selected per sample representing

210 regions within the plaque, adventitia, and perivascular adipose tissue (Figure 4B). There was

211 significant heterogeneity in areas within the plaque as some regions had predominantly

212 macrophages and others had predominantly $C D 3^{+} / C D 8^{+}$cells (Figure $4 C$ ). Images with single

213 fluorescent antibodies were included to show the macrophage and T cells within each AOI

214 (Supplementary Figure 2). In general, there was similar degree of heterogeneity in the HIV-

215 positive and HIV-negative plaques.

216 Using an optical barcode microscope, we obtained digital spatial protein expression data from

217 the coronary plaques of an HIV-positive and HIV-negative person. Molecular profiling using a

218 heatmap showed that adipose tissue AOls had similar protein expression profiles independent

219 of HIV-status (Figure 5A). Differential protein expression of all AOIs by HIV-status showed

220 higher Stimulator of interferon genes (STING), CD163, V-domain immunoglobulin suppressor of

221 T cell activation (VISTA), Bcl-2, Ki-67 and cytotoxic T-lymphocyte-associated protein 4 (CTLA-4)

$222(p<0.05)$ in the HIV-positive coronary plaque (Figure 5B-C).

223

\section{STING is highly expressed in macrophage-rich HIV-positive AOls}

225 We excluded the adipose tissue and adventitia (external AOls) and analyzed the differential

226 protein expression of AOls within the coronary plaque by HIV-status. These included 6 AOls

227 from the HIV-positive plaque and 7 AOls from the HIV-negative. Differential protein expression

228 by $t$-test showed significantly higher expression of STING, CD163, VISTA, GZMB, Ki-67, Bcl-2,

229 CD25, Tim-3, CD127 and CTLA4 in the HIV-positive coronary plaque AOls (Figure 6A), while

230 HLA-DR, CD14 was higher in the HIV-negative coronary plaque. The distribution of the different

231 AOls contributing to these main genes are shown by boxplot (Figure 6B). Due to the 
232 heterogeneity within the coronary plaques, we used the trend line to show variations in counts

233 by section in both the HIV-positive and negative. CD163 was highly expressed in all AOls

234 (Figure 6C). However, the segments that had the highest proportion of macrophages in the

235 HIV-positive sample (AOI 9 and 10) had the highest expression of STING. Notably although

236 lower expression of STING was present in the HIV-negative plaque, the regions with the highest

237 expression were also those with more macrophages (AOI 1,2 and 6). STING correlated with

238 activation $\left(C D 25, R^{2}=0.77 ;\right.$ Tim-3, $\left.R^{2}=0.83\right)$, naïve and memory $T$ cells $\left(C D 127, R^{2}=0.68\right)$,

239 macrophages $\left(C D 163, R^{2}=0.62\right)$. VISTA protein, which is associated with myeloid activation

240 and is a checkpoint inhibitor, expression was correlated with CD163 $R^{2}=0.82$ and GZMB $R^{2}=$

2410.71 (Figure 6C).

242

243 Analysis of segments external to the plaque (adipose and adventitia) showed higher levels of

244 B7-H3, fibronectin and CD34 expression in HIV-negative AOls. Heatmap of external segments

245 alone showed similarity in protein levels that clustered based on adipose tissue versus

246 adventitia (Figure 7A). Differential protein levels by $t$-test showed higher B7-H3, CD34 and

247 fibronectin in HIV-negative samples (Figure 7B). These proteins were highly prevalent in the

248 adipose tissue segments ( $\mathrm{AOI} 3,7,10$ and 12) and not the immune $\mathrm{T}$ cell rich segment in the

249 adventitia (AOI 5). CTLA4, STING and VISTA were found in high levels in immune cell rich AOls

250 in the adventitia (AOI 5 and 11) while CD163 was higher in an adipose AOI (4) and adventitia

251 AOI with macrophages and T cells (6) (Figure 7C).

252

253 CMV seroprevalence is significantly higher in PWH compared to HIV-negative individuals. ${ }^{50}$ It

254 has been proposed that PWH have a higher level of viral replication within tissue compartments

255 even in the absence of active viremia. Although DNA viruses are the main stimulators of STING

256 via cGAS, RNA viruses such as HIV may also stimulate STING via the retinoic acid-inducible

257 gene I (RIG-I) pathways. ${ }^{51}$ RIG-I is a cytosolic pattern recognition receptor that recognizes 
double stranded viral RNA. Our proposed hypothesis is that viral DNA and RNA in PLWH, possibly in combination with modified oxidized peptides are transiently activating STING-related pathways within coronary plaques of PLWH, leading to higher levels of inflammation and

261 increased plaque instability (Figure 8).

\section{DISCUSSION}

264 In this study, we hypothesized that coronary plaques from persons with HIV would have a 265 higher proportion of immune cells compared to HIV-negative. Furthermore, they would have an 266 immune profile that is consistent with stimulation by virus compared to coronary plaques from 267 HIV-negative individuals. Newer single-cell analysis has facilitated the investigation of the 268 heterogenous populations of cells present in atherosclerotic plaques. ${ }^{30}$ Understanding the 269 immune components is fundamental if we expect to develop immunotherapies that significantly

270 reduce atherosclerosis progression and CV events. Using GeoMX ${ }^{\circledR}$ digital profiling, we were

271 able to select regions that were enriched with macrophages, T cells, a combination

272 (macrophages and T cells) or perivascular adipose tissue. In general, the coronary plaque AOls

273 from the representative HIV-positive plaque had higher expression of STING compared to the

274 HIV-negative plaque AOls. This was even more pronounced in the AOls that were macrophage

275 rich.

276

277 Using coronary samples from HIV-positive and HIV-negative individuals, we quantified the

278 innate and adaptive immune cells within the coronary plaques and perivascular fat. We found a 279 higher frequency of total immune cells within coronary plaques of HIV-positive persons. CD163 280 cells were significantly higher by $\mathrm{IHC}$ and protein expression using GeoMX ${ }^{\circledR}$ digital profiling.

281 Notably, CD163 expression on monocytes and macrophages has been shown to confer 282 susceptibility of infection with both $\mathrm{DNA}^{39}$ and $\mathrm{RNA}^{40}$ viruses. There are no studies to date that 283 have looked at whether CD163+ macrophages are more permissive to CMV infection. HIV 
infected $\mathrm{CD}_{163^{+}} \mathrm{CD}^{+} 8^{+}$macrophages have been reported in gut biopsies from untreated PLWH while CMV was primarily detected in epithelial cells ${ }^{41}$. Ongoing studies using RNAscope will define the viral burden - HIV and CMV - within plaque tissue and in perivascular adipose tissue of PLWH to better understand the tissue pathology of these viruses in this context.

STING is an endoplasmic reticulum adaptor protein that can bind DNA viruses and intermediate DNA transcripts of RNA viruses initiating an innate immune inflammatory cascade leading to activate of type I interferons. ${ }^{52,53}$ The DNA viruses include CMV, Epstein Barr virus (EBV) and

292 herpes simplex virus (HSV). STING is a critical signaling molecule that is involved in tissue inflammation and has been shown to trigger metabolic stress-induced endothelial inflammation in a mouse model. STING agonists have been shown to activate cells that were latently infected with simian immunodeficiency virus (SIV) and enhanced SIV-specific responses in vivo ${ }^{54}$. It is possible that a similar effect would be seen with HIV. Thus, in individuals co-infected with HIV and CMV, re-reactivation of CMV might create a setting where HIV infection is enhanced with apoptosis of those $\mathrm{CD} 4^{+} \mathrm{T}$ cells. Notably, CMV-specific CD4 ${ }^{+} \mathrm{T}$ cells express CX3CR1, and a subset of these CMV-specific cells are protected from HIV-infection ${ }^{55}$. As a result, the CMVspecific cells are likely to accumulate with time in the setting of low levels of CMV replication in tissues. We have previously shown that CMV-specific CD4 ${ }^{+} \mathrm{T}$ cells were largely $\mathrm{T}$ effector memory cells $\mathrm{RA}^{+}$revertant ( $\mathrm{T}_{\mathrm{EMRA}}$ ) and $\mathrm{T}$ effector memory cells $\left(\mathrm{T}_{\mathrm{EM}}\right)$; cytotoxic with notable expression of GZMB and perforin at baseline. ${ }^{22}$ To our knowledge, the role of STING in atherosclerosis has not been reported by other groups. Our next steps are to perform a similar analysis on a larger number of samples and define the pathogen burden (both viral and bacterial) within coronary plaques of PLWH and HIV-negative. This will involve in situ staining 307 as well as droplet digital PCR to quantify DNA extracted from these samples. Identification of 308 replicating virus in the plaque can provide evidence for the need of CMV-specific antivirals in 309 this patient population or targeted inhibitors of the STING pathway. 
311 This study has several limitations. The deceased persons were confirmed HIV-positive and HIV-

312 negative. However, we do not have information on their ART regimens or viral load at the time

313 of death. Therefore, if we find virus in their coronary plaques, we will not be able to relate the

314 viral burden to their ART compliance. Furthermore, the samples are processed after

315 examination by the medical examiner, therefore there could be a slight delay from when the

316 patient died. Future studies using samples from living donors that are processed within 30

317 minutes to 1 hour of obtaining the sample are underway. Finally, for the digital spatial profiling,

318 we chose the individuals with the highest proportion of cells so that they would be comparable.

319 Some sections of the HIV-negative blood vessel had the appearance of a total chronic

320 occlusion. Based on our pathology analysis, we opted to match them based on the abundance

321 of immune cells. Future studies will include a larger number of participants and different stages

322 of atherosclerosis.

324 Conflict of interest

325 The authors have declared that no conflict of interest exists.

\section{Financial support}

328 This work was funded by NIH grants K23 100700 (JK), R01 DK112262 (JK and CW), HL131977

329 (JB), R56 DK108352 (JK), the Vanderbilt Clinical and Translational Science award from

330 NCRR/NIH grant UL1 RR024975, the Vanderbilt Infection Pathogenesis and Epidemiology

331 Research Training Program (VIPER) grant T32 AI007474, CTSA award no. KL2 TR002245 from

332 the National Center for Advancing Translational Sciences, and the Tennessee Center for AIDS

333 Research grant P30 Al110527. The funding authorities had no role in study design; data

334 collection, analysis, or interpretation; decision to publish; or preparation of the manuscript. 


\section{Author contributions}

337 Conceptualization, C.N.W., L.G., J.R.K., J.B., S.A.M.; Methodology, C.N.W., L.G., D.T.F., L.M.,

338 M.J.T., R.V., Y.L., J.G., A.V.F., S.B., C.L.G., M.M., S.A.M., J.B., J.R.K.; Statistics, C.N.W., J.G.,

339 L.M., J.R.K.; Formal Analysis, C.N.W., L.G., D.T.F., L.M., S.B., M.J.T., J.R.K. ; Investigation,

340 C.N.W., C.M.W., J.R. K; Resources, J.R.K., J.B., M.J.T., A.V.F., R.V., S.A.K., S.A.M.; Data

341 Curation, C.N.W., L.G., D.T.F., L.M., M.J.T., J. R. K.; Writing - Original Draft, C.N.W., L.G.,

342 J.R.K.; Writing - Review \& Editing, all authors; Visualization, C.N.W., L.G., D.T.M., M.J.T.,

343 J.R.K.; Supervision, J.R.K., L.G., R.V., A.V.F., M.J.T., S.A.M., S.A.K.; Project Administration,

344 J.R.K., J. B., S.A.K.; Funding Acquisition, C.N.W., A.V.F., M.J.T., J.R.K. 


\section{Bibliography}

1. Shah ASV, Stelzle D, Lee KK, Beck EJ, Alam S, Clifford S, Longenecker CT, Strachan F, Bagchi S, Whiteley W, Rajagopalan S, Kottilil S, Nair H, Newby DE, McAllister DA, Mills NL. Global burden of atherosclerotic cardiovascular disease in people living with hiv. Circulation. 2018;138:1100-1112

2. Currier JS, Taylor A, Boyd F, Dezii CM, Kawabata H, Burtcel B, Maa JF, Hodder S. Coronary heart disease in hiv-infected individuals. J Acquir Immune Defic Syndr. 2003;33:506-512

3. Triant VA, Lee $\mathrm{H}$, Hadigan C, Grinspoon SK. Increased acute myocardial infarction rates and cardiovascular risk factors among patients with human immunodeficiency virus disease. J Clin Endocrinol Metab. 2007;92:2506-2512

4. Hsue PY, Deeks SG, Hunt PW. Immunologic basis of cardiovascular disease in hivinfected adults. J Infect Dis. 2012;205 Suppl 3:S375-382

5. Freiberg MS, Chang CC, Kuller LH, Skanderson M, Lowy E, Kraemer KL, Butt AA, Bidwell Goetz M, Leaf D, Oursler KA, Rimland D, Rodriguez Barradas M, Brown S, Gibert C, McGinnis K, Crothers K, Sico J, Crane H, Warner A, Gottlieb S, Gottdiener J, Tracy RP, Budoff M, Watson C, Armah KA, Doebler D, Bryant K, Justice AC. Hiv infection and the risk of acute myocardial infarction. JAMA Intern Med. 2013;173:614-622

6. El-Sadr WM, Lundgren J, Neaton JD, Gordin F, Abrams D, Arduino RC, Babiker A, Burman W, Clumeck N, Cohen CJ, Cohn D, Cooper D, Darbyshire J, Emery S, Fätkenheuer G, Gazzard B, Grund B, Hoy J, Klingman K, Losso M, Markowitz N, Neuhaus J, Phillips A, Rappoport C, Group SfMoATSS. Cd4+ count-guided interruption of antiretroviral treatment. N Engl J Med. 2006;355:2283-2296

7. Pothineni NVK, Subramany S, Kuriakose K, Shirazi LF, Romeo F, Shah PK, Mehta JL. Infections, atherosclerosis, and coronary heart disease. Eur Heart J. 2017;38:3195-3201

8. Armah KA, McGinnis K, Baker J, Gibert C, Butt AA, Bryant KJ, Goetz M, Tracy R, Oursler KK, Rimland D, Crothers K, Rodriguez-Barradas M, Crystal S, Gordon A, Kraemer K, Brown S, Gerschenson M, Leaf DA, Deeks SG, Rinaldo C, Kuller LH, Justice A, Freiberg M. Hiv status, burden of comorbid disease, and biomarkers of inflammation, altered coagulation, and monocyte activation. Clin Infect Dis. 2012;55:126-136

9. Hunt PW, Brenchley J, Sinclair E, McCune JM, Roland M, Page-Shafer K, Hsue P, Emu B, Krone M, Lampiris H, Douek D, Martin JN, Deeks SG. Relationship between t cell activation and cd4+ $\mathrm{t}$ cell count in hiv-seropositive individuals with undetectable plasma hiv rna levels in the absence of therapy. $J$ Infect Dis. 2008;197:126-133

10. Duprez DA, Neuhaus J, Kuller LH, Tracy R, Belloso W, De Wit S, Drummond F, Lane HC, Ledergerber B, Lundgren J, Nixon D, Paton NI, Prineas RJ, Neaton JD, Group ISS. Inflammation, coagulation and cardiovascular disease in hiv-infected individuals. PLoS One. 2012;7:e44454

11. De Luca A, de Gaetano Donati K, Colafigli M, Cozzi-Lepri A, De Curtis A, Gori A, Sighinolfi L, Giacometti A, Capobianchi MR, D'Avino A, lacoviello L, Cauda R, D'Arminio Monforte $A$. The association of high-sensitivity c-reactive protein and other biomarkers with cardiovascular disease in patients treated for hiv: A nested case-control study. BMC Infect Dis. 2013;13:414 
12. Triant VA, Meigs JB, Grinspoon SK. Association of c-reactive protein and hiv infection with acute myocardial infarction. J Acquir Immune Defic Syndr. 2009;51:268-273

13. Hsue PY, Hunt PW, Schnell A, Kalapus SC, Hoh R, Ganz P, Martin JN, Deeks SG. Role of viral replication, antiretroviral therapy, and immunodeficiency in hiv-associated atherosclerosis. AIDS. 2009;23:1059-1067

14. Tawakol A, Ishai A, Li D, Takx RA, Hur S, Kaiser Y, Pampaloni M, Rupert A, Hsu D, Sereti I, Fromentin R, Chomont N, Ganz P, Deeks SG, Hsue PY. Association of arterial and lymph node inflammation with distinct inflammatory pathways in human immunodeficiency virus infection. JAMA Cardiol. 2017;2:163-171

15. Yarasheski KE, Laciny E, Overton ET, Reeds DN, Harrod M, Baldwin S, Dávila-Román VG. $18 \mathrm{fdg}$ pet-ct imaging detects arterial inflammation and early atherosclerosis in hivinfected adults with cardiovascular disease risk factors. J Inflamm (Lond). 2012;9:26

16. Spyridopoulos I, Martin-Ruiz C, Hilkens C, Yadegarfar ME, Isaacs J, Jagger C, Kirkwood T, von Zglinicki T. Cmv seropositivity and t-cell senescence predict increased cardiovascular mortality in octogenarians: Results from the newcastle 85+ study. Aging Cell. 2016;15:389-392

17. Olson NC, Sitlani CM, Doyle MF, Huber SA, Landay AL, Tracy RP, Psaty BM, Delaney JA. Innate and adaptive immune cell subsets as risk factors for coronary heart disease in two population-based cohorts. Atherosclerosis. 2020;300:47-53

18. Baker JV, Peng G, Rapkin J, Abrams DI, Silverberg MJ, MacArthur RD, Cavert WP, Henry WK, Neaton JD, (CPCRA) TBCPfCRoA. Cd4+ count and risk of non-aids diseases following initial treatment for hiv infection. AIDS. 2008;22:841-848

19. Ho JE, Deeks SG, Hecht FM, Xie Y, Schnell A, Martin JN, Ganz P, Hsue PY. Initiation of antiretroviral therapy at higher nadir cd4+t-cell counts is associated with reduced arterial stiffness in hiv-infected individuals. AIDS. 2010;24:1897-1905

20. Hsue PY, Lo JC, Franklin A, Bolger AF, Martin JN, Deeks SG, Waters DD. Progression of atherosclerosis as assessed by carotid intima-media thickness in patients with hiv infection. Circulation. 2004;109:1603-1608

21. Medina S, Wessman D, Krause D, Stepenosky J, Boswell G, Crum-Cianflone N. Coronary aging in hiv-infected patients. Clin Infect Dis. 2010;51:990-993

22. Abana CO, Pilkinton MA, Gaudieri S, Chopra A, McDonnell WJ, Wanjalla C, Barnett L, Gangula R, Hager C, Jung DK, Engelhardt BG, Jagasia MH, Klenerman P, Phillips EJ, Koelle DM, Kalams SA, Mallal SA. Cytomegalovirus (cmv) epitope-specific cd4(+) t cells are inflated in hiv(+) cmv(+) subjects. J Immunol. 2017;199:3187-3201

23. Hunt PW, Martin JN, Sinclair E, Epling L, Teague J, Jacobson MA, Tracy RP, Corey L, Deeks SG. Valganciclovir reduces t cell activation in hiv-infected individuals with incomplete cd4+t cell recovery on antiretroviral therapy. J Infect Dis. 2011;203:1474-1483

24. Hsue PY, Hunt PW, Sinclair E, Bredt B, Franklin A, Killian M, Hoh R, Martin JN, McCune JM, Waters DD, Deeks SG. Increased carotid intima-media thickness in hiv patients is associated with increased cytomegalovirus-specific t-cell responses. AIDS. 2006;20:2275-2283

25. Parrinello CM, Sinclair E, Landay AL, Lurain N, Sharrett AR, Gange SJ, Xue X, Hunt PW, Deeks SG, Hodis HN, Kaplan RC. Cytomegalovirus immunoglobulin g antibody is 
associated with subclinical carotid artery disease among hiv-infected women. $J$ Infect Dis. 2012;205:1788-1796

26. Koch S, Larbi A, Derhovanessian E, Ozcelik D, Naumova E, Pawelec G. Multiparameter flow cytometric analysis of cd4 and cd8 $t$ cell subsets in young and old people. Immun Ageing. 2008;5:6

27. Chen B, Morris SR, Panigrahi S, Michaelson GM, Wyrick JM, Komissarov AA, Potashnikova D, Lebedeva A, Younes SA, Harth K, Kashyap VS, Vasilieva E, Margolis L, Zidar DA, Sieg SF, Shive CL, Funderburg NT, Gianella S, Lederman MM, Freeman ML. Cytomegalovirus coinfection is associated with increased vascular-homing cd57. $J$ Immunol. 2020

28. Libby P, Ridker PM, Hansson GK. Progress and challenges in translating the biology of atherosclerosis. Nature. 2011;473:317-325

29. Cochain C, Vafadarnejad E, Arampatzi P, Pelisek J, Winkels H, Ley K, Wolf D, Saliba AE, Zernecke A. Single-cell rna-seq reveals the transcriptional landscape and heterogeneity of aortic macrophages in murine atherosclerosis. Circ Res. 2018;122:1661-1674

30. Fernandez DM, Rahman AH, Fernandez NF, Chudnovskiy A, Amir ED, Amadori L, Khan NS, Wong CK, Shamailova R, Hill CA, Wang Z, Remark R, Li JR, Pina C, Faries C, Awad AJ, Moss N, Bjorkegren JLM, Kim-Schulze S, Gnjatic S, Ma'ayan A, Mocco J, Faries P, Merad $\mathrm{M}$, Giannarelli $\mathrm{C}$. Single-cell immune landscape of human atherosclerotic plaques. Nat Med. 2019;25:1576-1588

31. Lebedeva A, Vorobyeva D, Vagida M, Ivanova O, Felker E, Fitzgerald W, Danilova N, Gontarenko V, Shpektor A, Vasilieva E, Margolis L. Ex vivo culture of human atherosclerotic plaques: A model to study immune cells in atherogenesis. Atherosclerosis. 2017;267:90-98

32. Zhou X, Stemme S, Hansson GK. Evidence for a local immune response in atherosclerosis. $\mathrm{Cd} 4+\mathrm{t}$ cells infiltrate lesions of apolipoprotein-e-deficient mice. Am J Pathol. 1996;149:359-366

33. Mach F, Sauty A, Iarossi AS, Sukhova GK, Neote K, Libby P, Luster AD. Differential expression of three $t$ lymphocyte-activating $\mathrm{cxc}$ chemokines by human atheromaassociated cells. J Clin Invest. 1999;104:1041-1050

34. Wanjalla CN, McDonnell WJ, Barnett L, Simmons JD, Furch BD, Lima MC, Woodward BO, Fan R, Fei Y, Baker PG, Ram R, Pilkinton MA, Mashayekhi M, Brown NJ, Mallal SA, Kalams SA, Koethe JR. Adipose tissue in persons with hiv is enriched for cd4. Front Immunol. 2019;10:408

35. Kramer MC, Rittersma SZ, de Winter RJ, Ladich ER, Fowler DR, Liang YH, Kutys R, CarterMonroe N, Kolodgie FD, van der Wal AC, Virmani R. Relationship of thrombus healing to underlying plaque morphology in sudden coronary death. J Am Coll Cardiol. 2010;55:122-132

36. Guo L, Akahori H, Harari E, Smith SL, Polavarapu R, Karmali V, Otsuka F, Gannon RL, Braumann RE, Dickinson MH, Gupta A, Jenkins AL, Lipinski MJ, Kim J, Chhour P, de Vries $P S$, Jinnouchi $H$, Kutys R, Mori H, Kutyna MD, Torii S, Sakamoto A, Choi CU, Cheng $Q$, Grove ML, Sawan MA, Zhang Y, Cao Y, Kolodgie FD, Cormode DP, Arking DE, Boerwinkle E, Morrison AC, Erdmann J, Sotoodehnia N, Virmani R, Finn AV. Cd163+ macrophages 
promote angiogenesis and vascular permeability accompanied by inflammation in atherosclerosis. J Clin Invest. 2018;128:1106-1124

37. Kristiansen M, Graversen JH, Jacobsen C, Sonne O, Hoffman HJ, Law SK, Moestrup SK. Identification of the haemoglobin scavenger receptor. Nature. 2001;409:198-201

38. Burdo TH, Lo J, Abbara S, Wei J, DeLelys ME, Preffer F, Rosenberg ES, Williams KC, Grinspoon S. Soluble cd163, a novel marker of activated macrophages, is elevated and associated with noncalcified coronary plaque in hiv-infected patients. J Infect Dis. 2011;204:1227-1236

39. Sánchez-Torres C, Gómez-Puertas P, Gómez-del-Moral M, Alonso F, Escribano JM, Ezquerra A, Domínguez J. Expression of porcine cd163 on monocytes/macrophages correlates with permissiveness to african swine fever infection. Arch Virol. 2003;148:2307-2323

40. Calvert JG, Slade DE, Shields SL, Jolie R, Mannan RM, Ankenbauer RG, Welch SK. Cd163 expression confers susceptibility to porcine reproductive and respiratory syndrome viruses. J Virol. 2007;81:7371-7379

41. Maidji E, Somsouk M, Rivera JM, Hunt PW, Stoddart CA. Replication of $\mathrm{cmv}$ in the gut of hiv-infected individuals and epithelial barrier dysfunction. PLoS Pathog. 2017;13:e1006202

42. Vita S, Lichtner M, Marchetti G, Mascia C, Merlini E, Cicconi P, Vullo V, Viale P, Costantini A, D'Arminio Monforte A, Group fIFS. Brief report: Soluble cd163 in cmv-infected and cmv-uninfected subjects on virologically suppressive antiretroviral therapy in the icona cohort. J Acquir Immune Defic Syndr. 2017;74:347-352

43. Foussat A, Bouchet-Delbos L, Berrebi D, Durand-Gasselin I, Coulomb-L'Hermine A, Krzysiek R, Galanaud P, Levy Y, Emilie D. Deregulation of the expression of the fractalkine/fractalkine receptor complex in hiv-1-infected patients. Blood. 2001;98:16781686

44. Sacre K, Hunt PW, Hsue PY, Maidji E, Martin JN, Deeks SG, Autran B, McCune JM. A role for cytomegalovirus-specific cd4+cx3cr1+t cells and cytomegalovirus-induced t-cell immunopathology in hiv-associated atherosclerosis. AIDS. 2012;26:805-814

45. Lee M, Lee Y, Song J, Lee J, Chang SY. Tissue-specific role of cx. Immune Netw. 2018;18:e5

46. McDermott DH, Halcox JP, Schenke WH, Waclawiw MA, Merrell MN, Epstein N, Quyyumi AA, Murphy PM. Association between polymorphism in the chemokine receptor $\mathrm{cx} 3 \mathrm{cr} 1$ and coronary vascular endothelial dysfunction and atherosclerosis. Circ Res. 2001;89:401-407

47. Moatti D, Faure S, Fumeron F, Amara MI-W, Seknadji P, McDermott DH, Debré $P$, Aumont MC, Murphy PM, de Prost $D$, Combadière $C$. Polymorphism in the fractalkine receptor $\mathrm{cx} 3 \mathrm{cr} 1$ as a genetic risk factor for coronary artery disease. Blood. 2001;97:1925-1928

48. Stolla M, Pelisek J, von Brühl ML, Schäfer A, Barocke V, Heider P, Lorenz M, Tirniceriu A, Steinhart A, Bauersachs J, Bray PF, Massberg S, Schulz C. Fractalkine is expressed in early and advanced atherosclerotic lesions and supports monocyte recruitment via cx3cr1. PLoS One. 2012;7:e43572 
49. Combadière $B$, Faure $S$, Autran $B$, Debré $P$, Combadière $C$. The chemokine receptor cx3cr1 controls homing and anti-viral potencies of cd8 effector-memory t lymphocytes in hiv-infected patients. AIDS. 2003;17:1279-1290

50. Hoehl S, Berger A, Ciesek S, Rabenau HF. Thirty years of cmv seroprevalence-a longitudinal analysis in a german university hospital. Eur J Clin Microbiol Infect Dis. 2020;39:1095-1102

51. Ahn J, Barber GN. Sting signaling and host defense against microbial infection. Exp Mol Med. 2019;51:1-10

52. Zhong B, Yang Y, Li S, Wang YY, Li Y, Diao F, Lei C, He X, Zhang L, Tien P, Shu HB. The adaptor protein mita links virus-sensing receptors to irf3 transcription factor activation. Immunity. 2008;29:538-550

53. Ishikawa $\mathrm{H}$, Barber GN. Sting is an endoplasmic reticulum adaptor that facilitates innate immune signalling. Nature. 2008;455:674-678

54. Yamamoto T, Kanuma T, Takahama S, Okamura T, Moriishi E, Ishii KJ, Terahara K, Yasutomi Y. Sting agonists activate latently infected cells and enhance siv-specific responses ex vivo in naturally siv controlled cynomolgus macaques. Sci Rep. 2019;9:5917

55. Casazza JP, Brenchley JM, Hill BJ, Ayana R, Ambrozak D, Roederer M, Douek DC, Betts $\mathrm{MR}$, Koup RA. Autocrine production of beta-chemokines protects $\mathrm{cmv}$-specific cd4 t cells from hiv infection. PLoS Pathog. 2009;5:e1000646 


\section{Digital spatial profiling of coronary plaques from persons living with HIV reveals high levels of STING and CD163 in macrophage enriched regions}

Celestine N. Wanjalla ${ }^{1,8}$, Liang Guo ${ }^{2}$, Daniela T. Fuller ${ }^{2}$, Mona Mashayekhi ${ }^{3}$, Samuel Bailin ${ }^{1}$, Curtis L. Gabriel ${ }^{4}$, Tecla Temu ${ }^{5}$, Jingjing Gong ${ }^{6}$, Yan Liang ${ }^{6}$, Renu Virmani $^{2}$, Aloke V. Finn ${ }^{2}$, Spyros A. Kalams ${ }^{1,9}$, Simon A. Mallal ${ }^{1,7,8}$, Jonathan J. Miner ${ }^{9}$, Joshua A. Beckman ${ }^{10}$, John R. Koethe ${ }^{1,8,12}$

HIV-Negative

A)

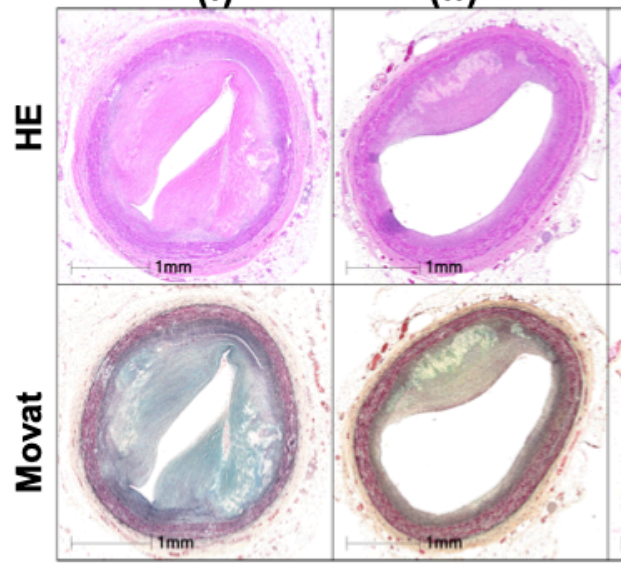

(iii)

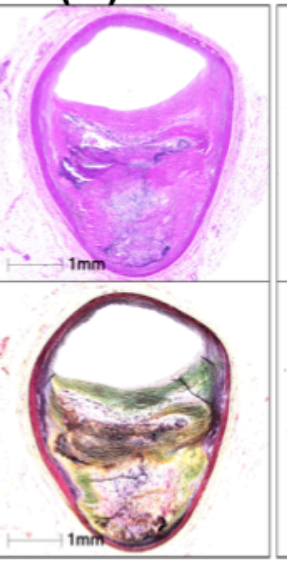

HIV-Positive

(i)

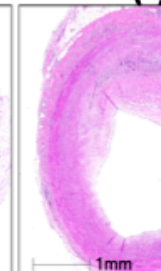

(ii)

(iii)

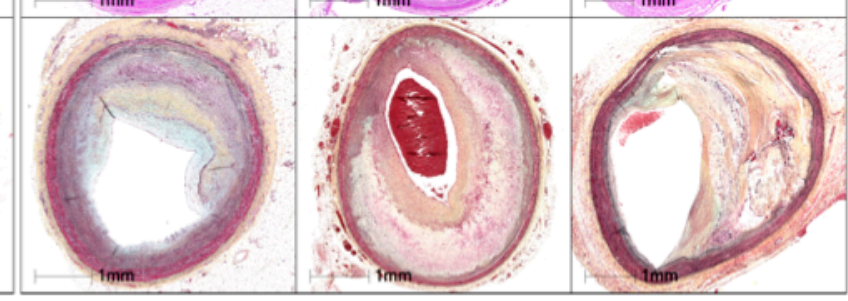

B)
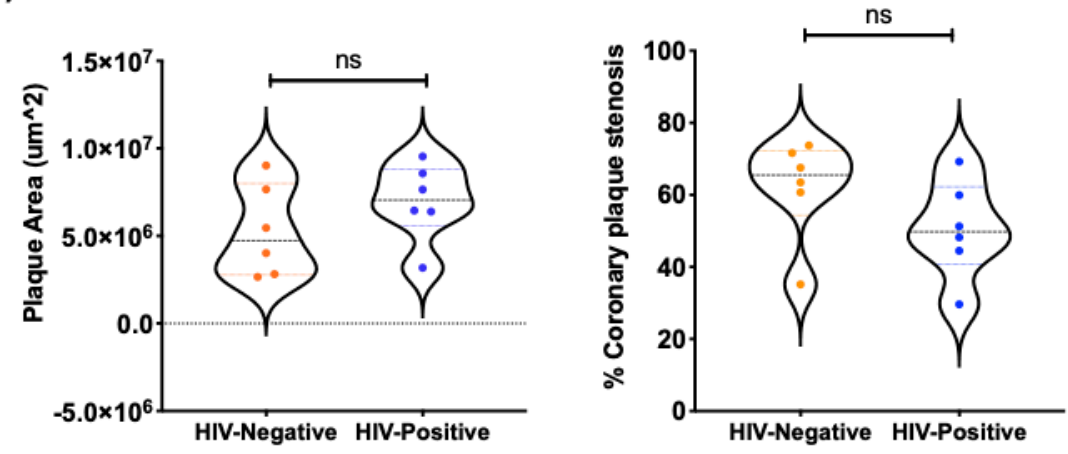

Figure 1. Characterization of coronary plaques. Representative coronary plaques from three HIV-positive and three HIV-negative individuals were stained with H\&E and Movat stain (A). Plaque area $\left(\mu \mathrm{m}^{2}\right)$ and \% plaque stenosis were measured and calculated in 6 individuals per group (B). Statistical analysis, Mann-Whitney; ns not significant 


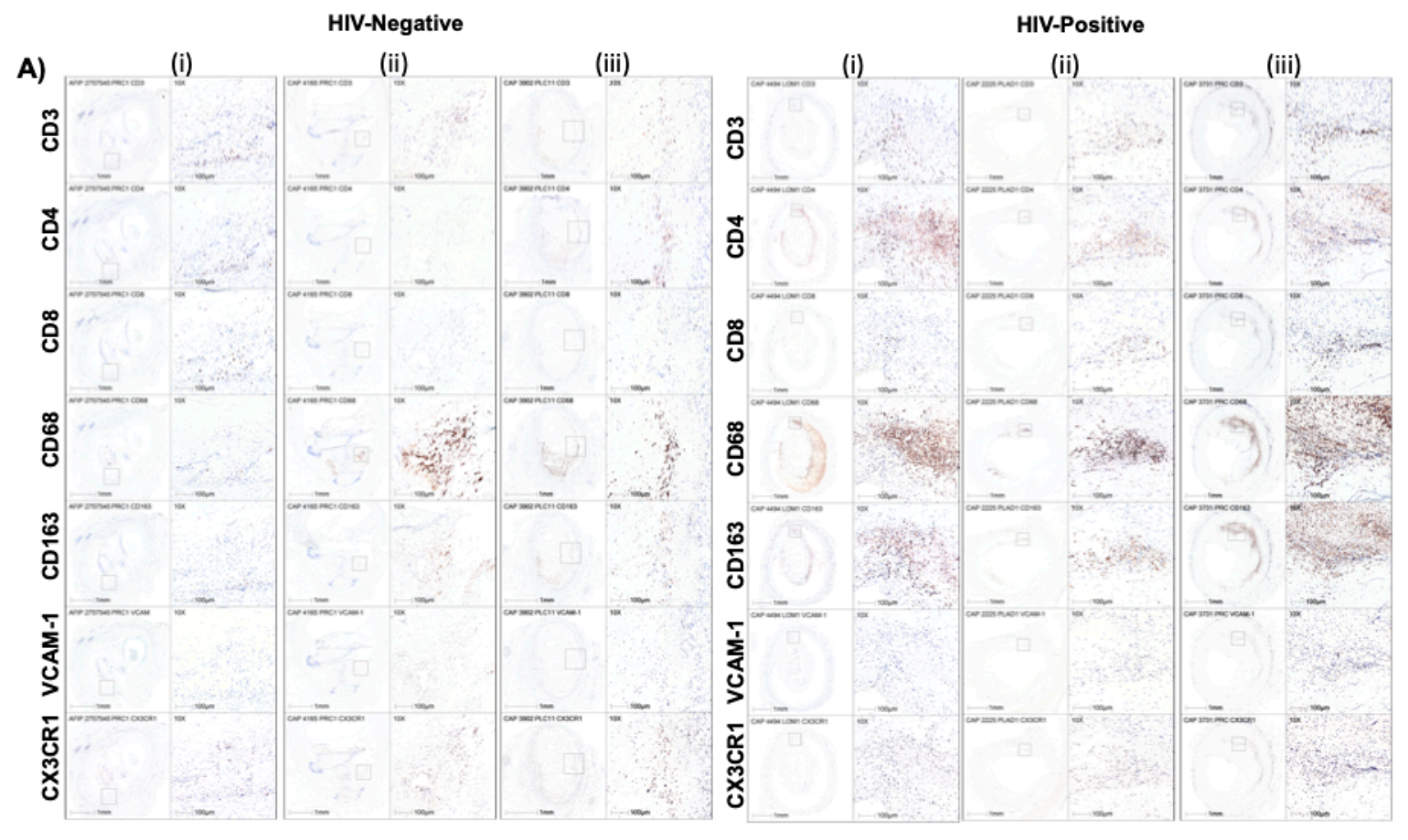

B)

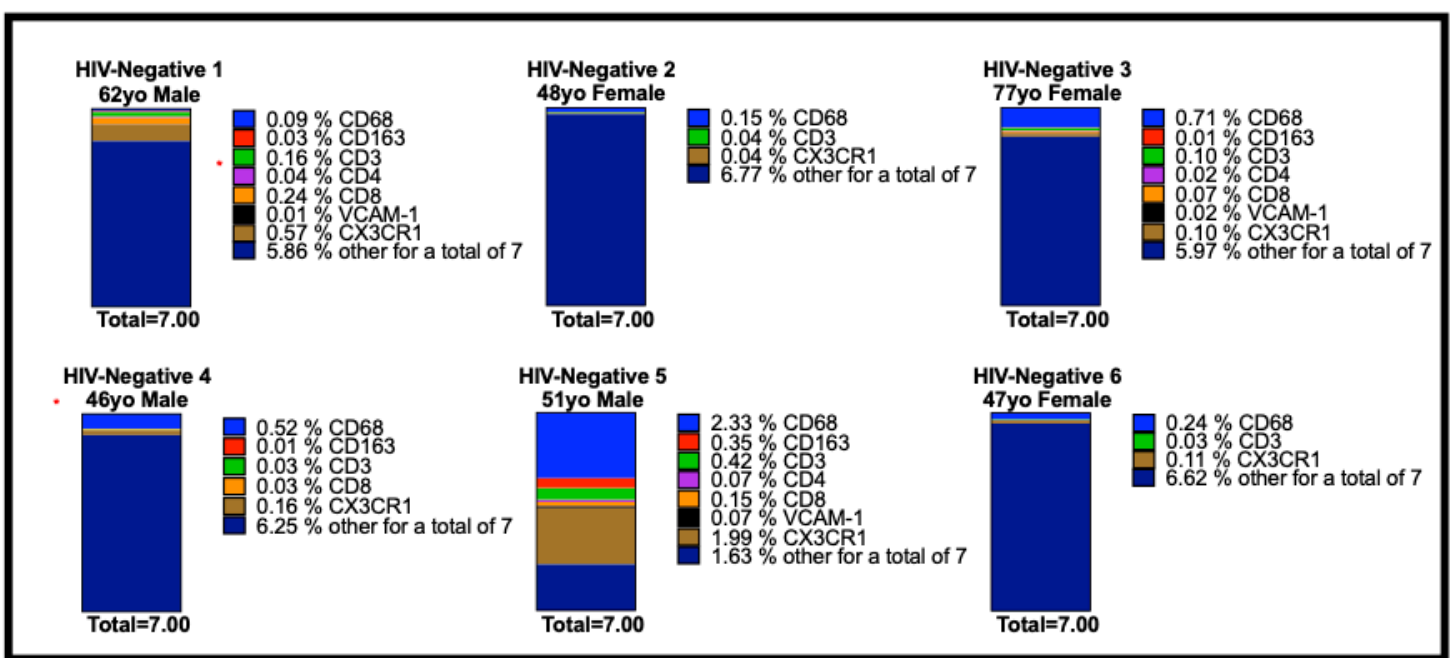

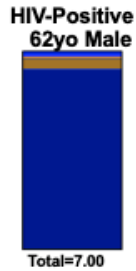

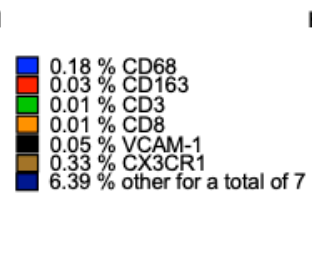

HIV-Positive 4 49yo Male

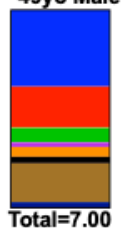

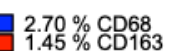

$0.52 \%$ CD 3

$0.16 \%$ CD 4

$0.35 \%$ CD8
$0.23 \%$ VCAM- 1

$0.23 \%$ VCAM-1
$1.37 \%$ CX3CR 1

$1.37 \%$ CX3CR 1
$0.20 \%$ other for a total of 7
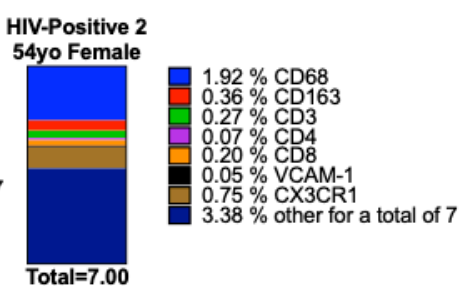

HIV-Positive 5
50 yo Male

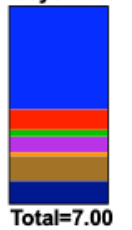

HIV-Positive 3

74 yo Female

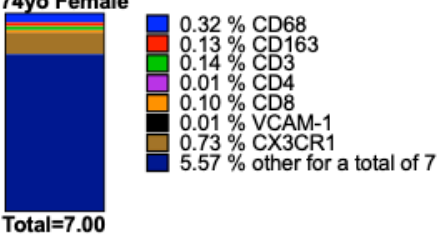

HIV-Positive 6

$3.66 \%$ CD68

$0.72 \%$ CD163

$0.24 \%$ CD3

$0.55 \%$ CD4

$0.88 \%$ CX3CR 1

$0.80 \%$ other for a total of 7
$1.24 \%$ CD68
$0.21 \%$ CD163

$0.14 \% \mathrm{CD} 3$

$0.13 \%$ CD4
$0.25 \%$ CD8

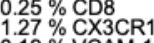

44 yo Female

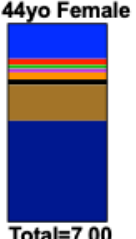


Figure 2. Coronary plaque immune cell constituents in HIV-positive and HIV-negative persons. IHC stains of CD3, CD4, CD8, CD68, CD163, VCAM-1 and CX3CR1 in three out of six representative coronary plaques from HIV-positive and negative deceased persons (A). The percentage of $\mathrm{CD} 8^{+}, \mathrm{CX} 3 \mathrm{CR} 1^{+}, \mathrm{CD} 8^{+}, \mathrm{CD}^{+}, \mathrm{VCAM}-1^{+}$and $\mathrm{CD} 163^{+}$were determined and displayed using a stacked bar chart showing additive percentage of immune cells/um in each individual. The highest total percentage of cells was $\sim 7 \%$, which was used as the total in in all individuals to allow for direct comparisons (B). Coronary plaques labeled HIV-Negative \#5 and HIV-Positive \#4 (marked by red *) were selected for digital spatial profiling. 

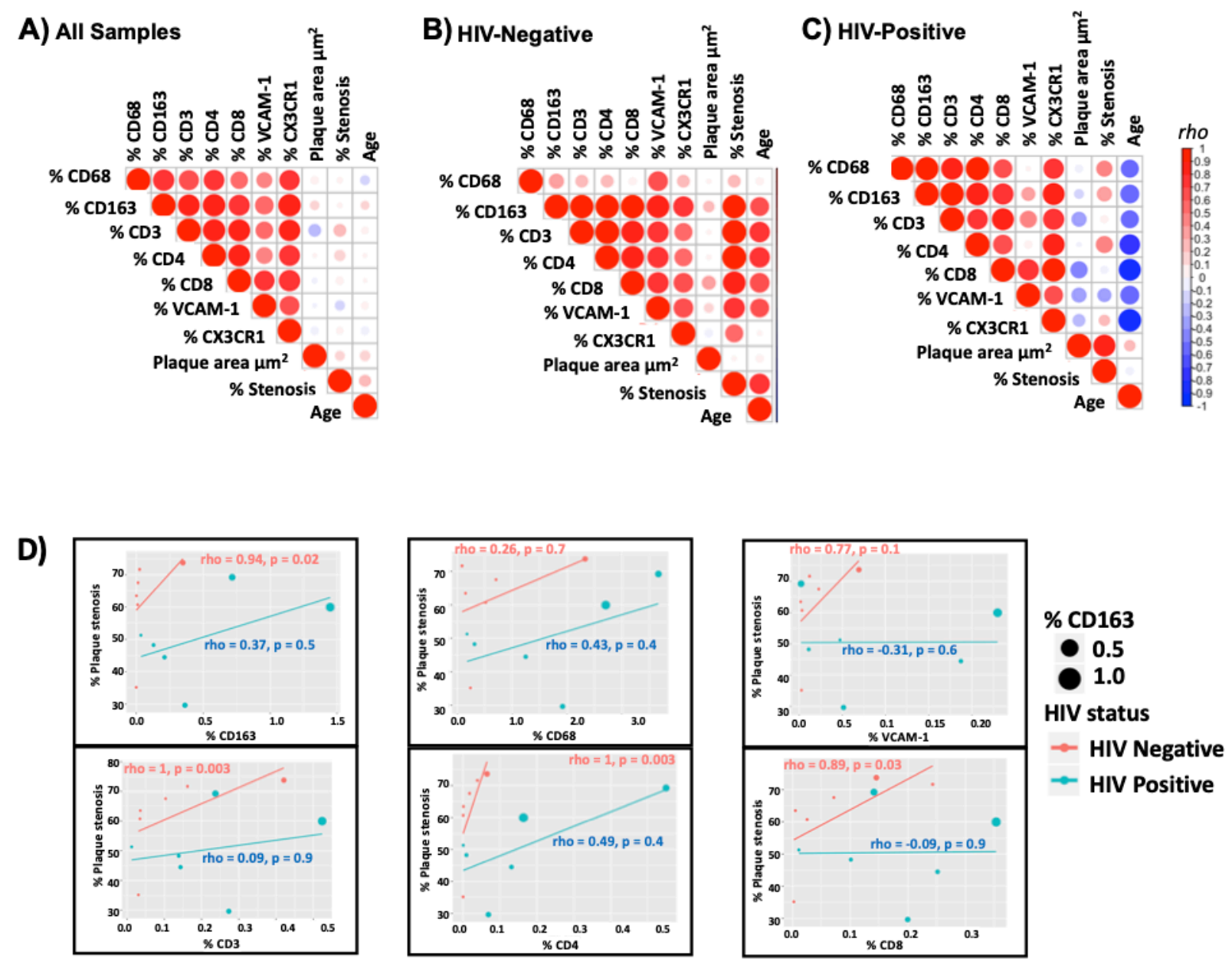

Figure 3. There is a positive correlation between plaque stenosis and CD163, CD3, CD4 and CD8 in HIV-negative coronary samples and not HIV-positive. Correlation matrices between immune cells in all samples (A), HIV-positive (B) and HIV-negative (C) were generated in $r$ using the corrplot package. Spearman rank correlation analysis of plaque stenosis and each of the immune subsets was also done on $r$, the size of the dots represent the percentage of $\mathrm{CD}_{163^{+}}$cells in that specific sample (D). Statistical analysis, spearman correlation analysis, $\mathrm{P}<$ 0.05 significant. 
A)

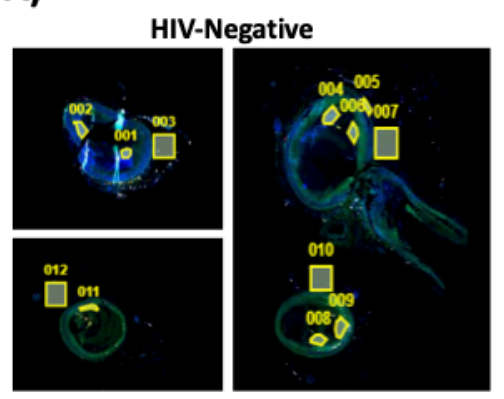

HIV-Positive

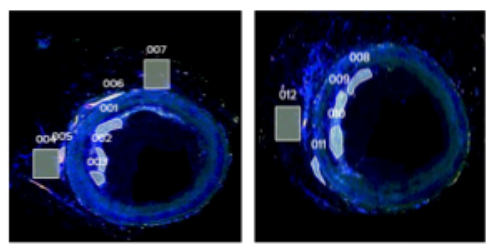

B)
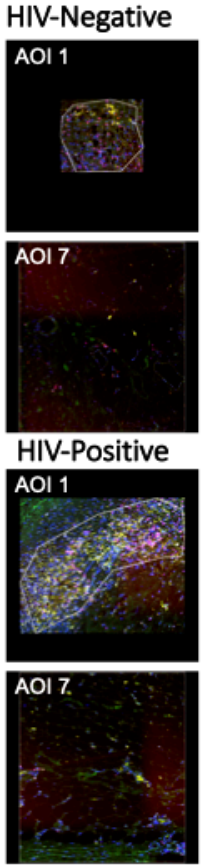
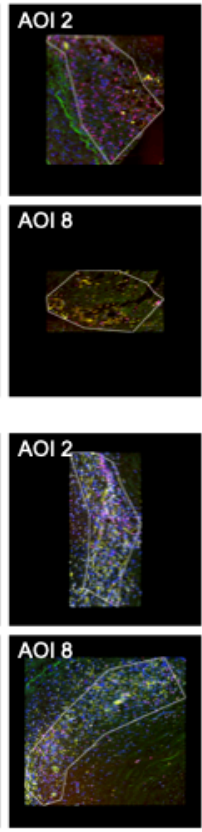
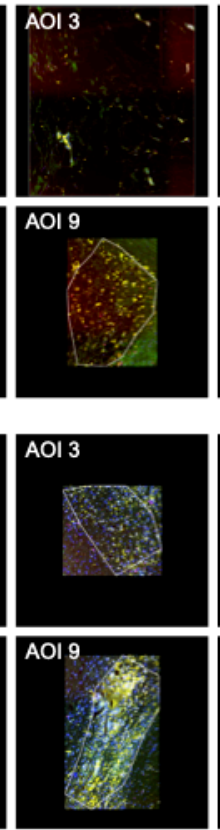
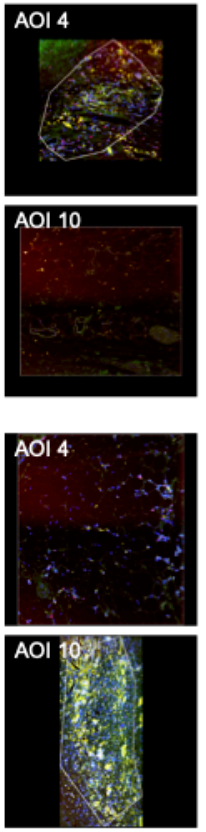
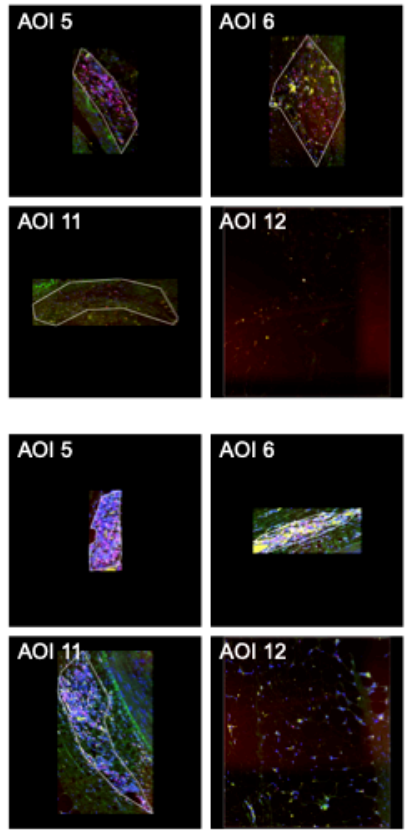

DAPI, CD3, CD8, CD68

C) HIV-negative
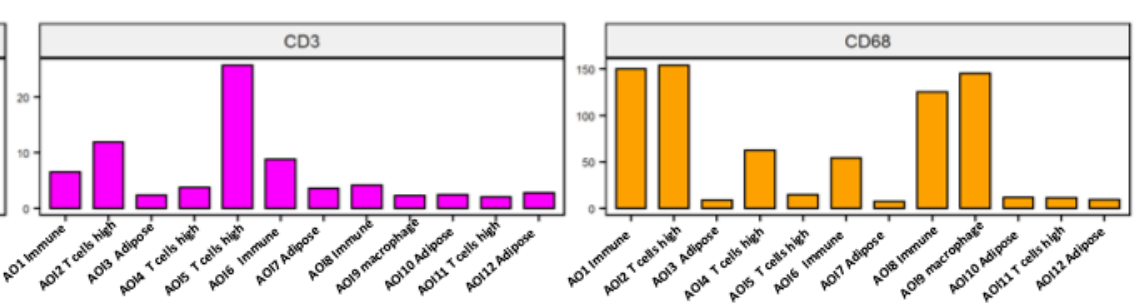

HIV-positive
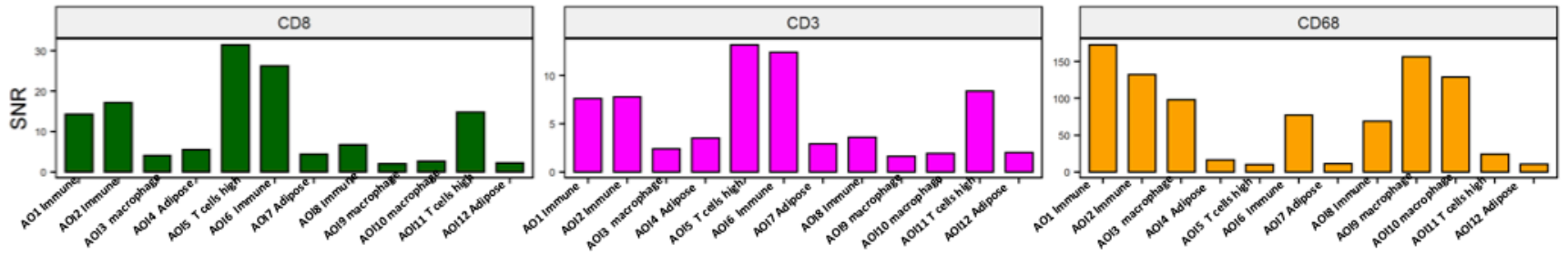

Figure 4. Digital spatial profiling of immune-related proteins in coronary plaques from HIV-positive and HIV-negative individuals. Twelve ROI per sample (HIV-positive and negative) were selected for analysis. Geometric regions of varying sizes were used to select regions of interest within the plaque, in the adventitia and perivascular adipose tissue. (A). Each sample was stained with anti-CD3 (pink), antiCD8 (green) and anti-CD68 (yellow). SYTO 83 nuclear staining was included to visualize all cells. The twelve different regions selected per sample are designated as area of interest (AOI 1-12) are shown (B). Signal to noise ratio normalized barcode counts of the three fluorescently tagged markers across all 12AOls demonstrate heterogeneity of coronary plaques in both groups (C). 
A)

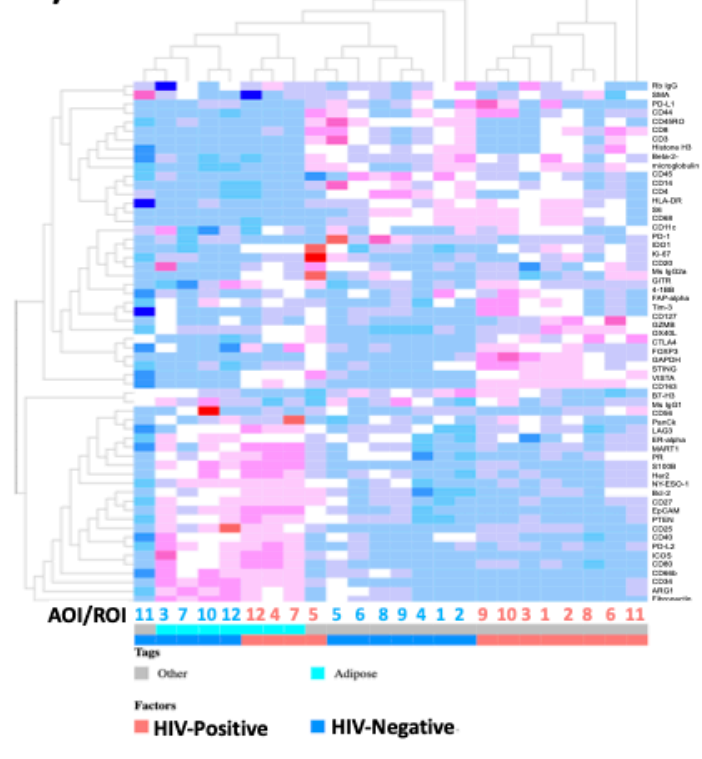

C)

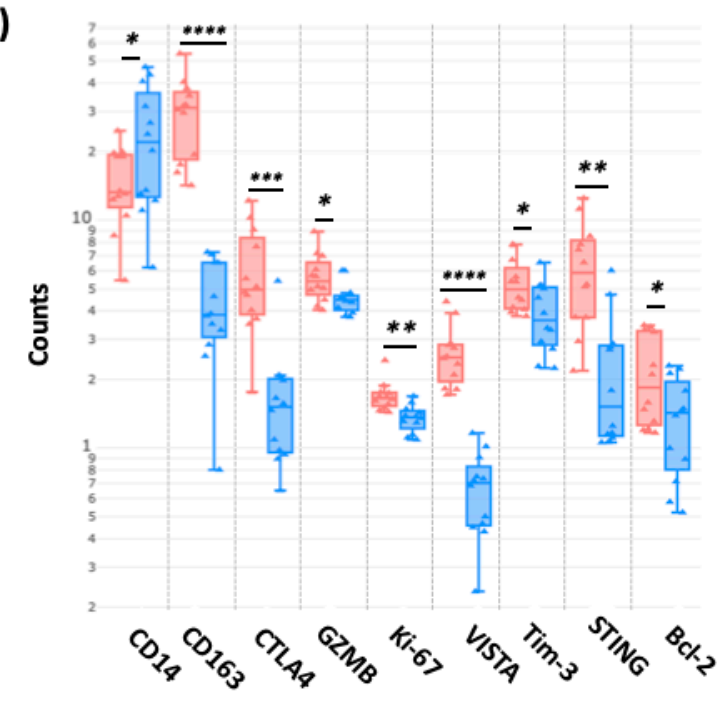

B)
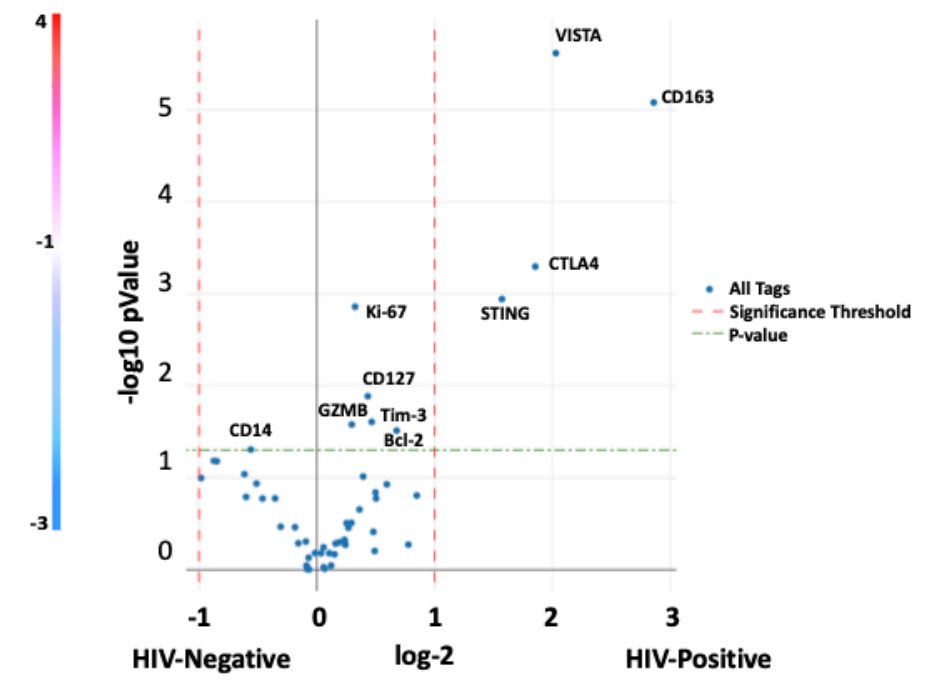

HIV-Positive

HIV-Negative

Figure 5. Digital spatial imaging analysis shows clustering of adipose tissue segments independent of HIV-status. A dendrogram grouping area of interest (AOI) segments that have similar protein expression (A). Differential protein expression of all segments by HIV-status (B). Box plots showing STING, VISTA, CD127, Bcl-3, Ki-67 and CD163, higher in HIV-positive and CD14, higher in HIVnegative AOl's (C). Significance determined by t-test, and $\mathrm{BH}$ correction $p<0.05$ significant. 
A)

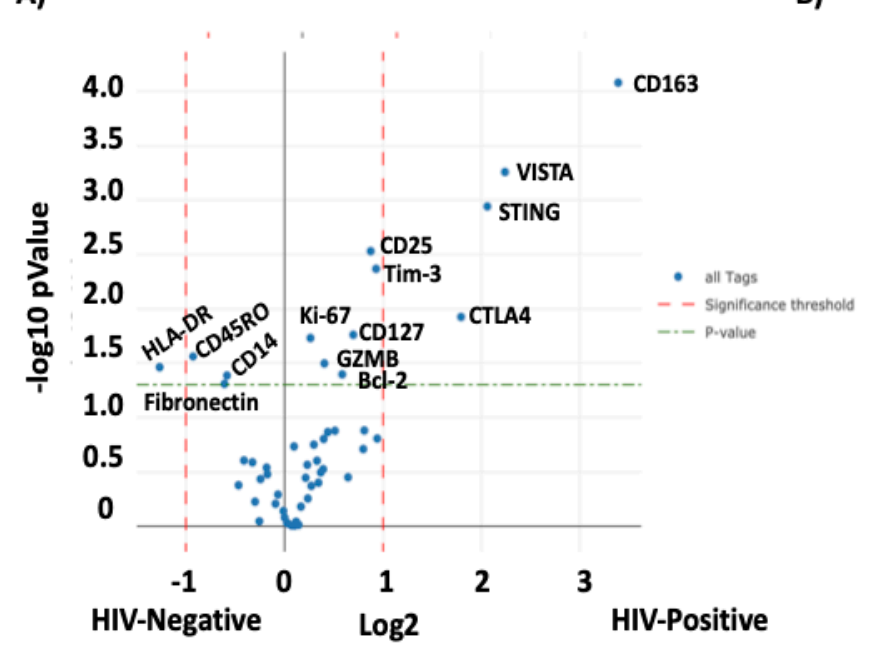

B)

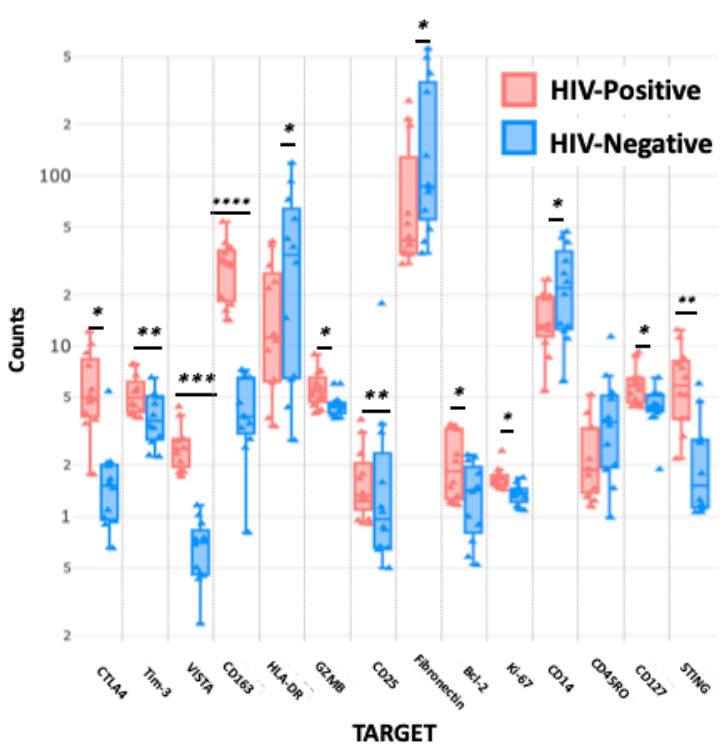

C)
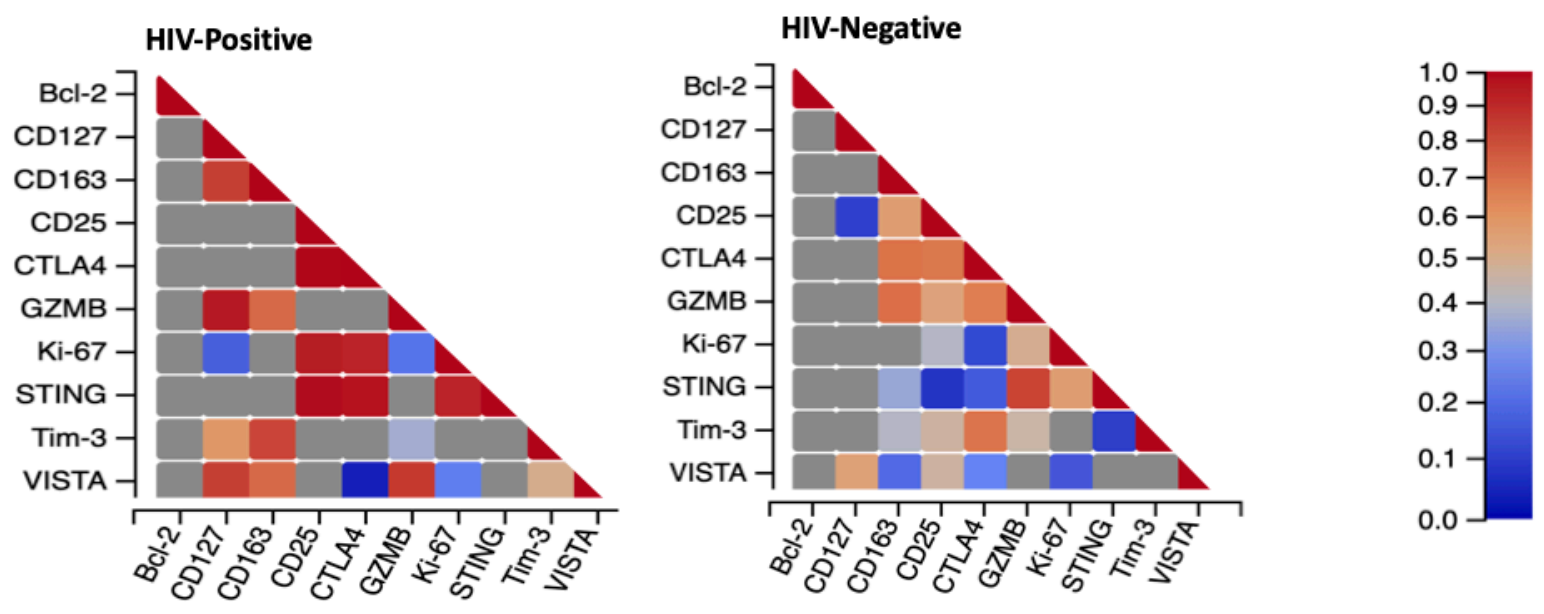

Figure 6. STING, CD163 and VISTA protein expression levels are higher in HIV-positive coronary plaque AOl's. Violin plot showing differential protein expression between HIVpositive and HIV-Negative AOls within the plaque (A). Box plot showing the median counts of the proteins that were significantly higher in HIV-negative and positive samples $(B)$. There is a positive correlation between STING protein expression and Ki-67 both HIV-positive and HIVnegative coronary plaque samples, and CD25, CTLA4 in the HIV-positive (C). Statistical analysis, t-test with $\mathrm{BH}$ correction, (green dashed line) $p<0.05$ and red dashed lines (fold change > 1). 
A)

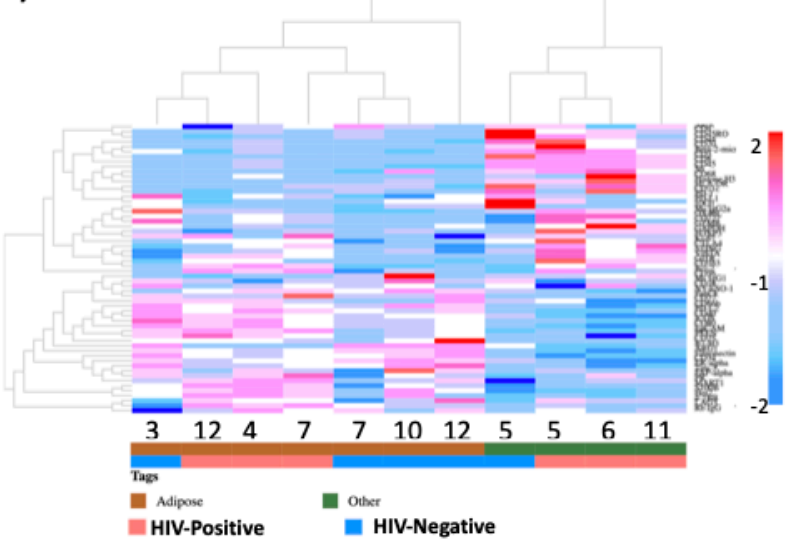

B)

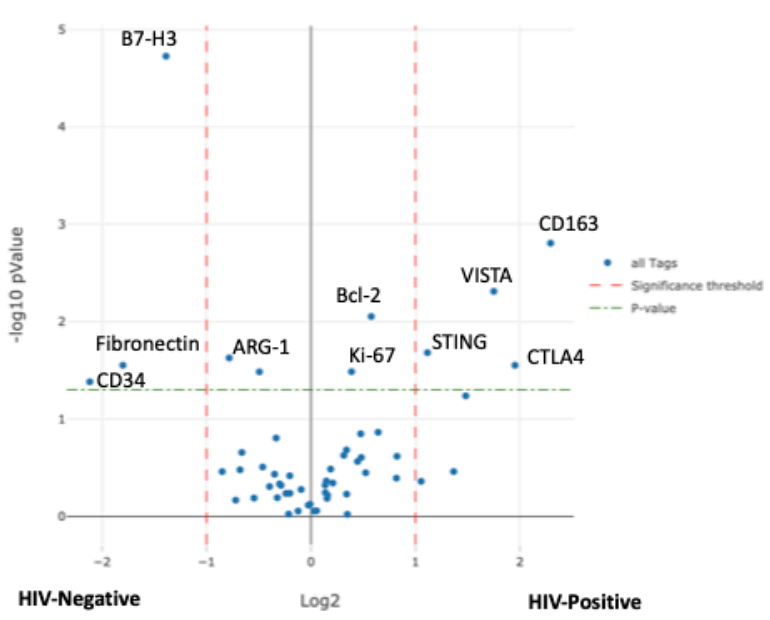

C) Adipose tissue and Adventitia HIV-Negative
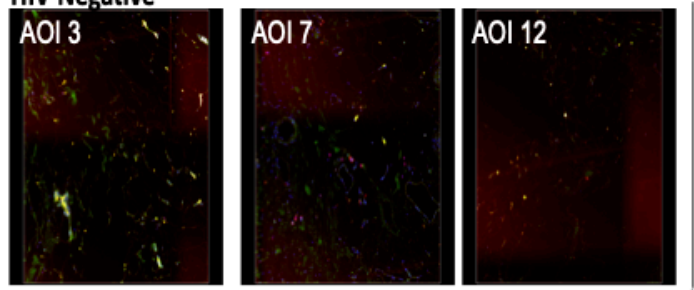

HIV-Positive
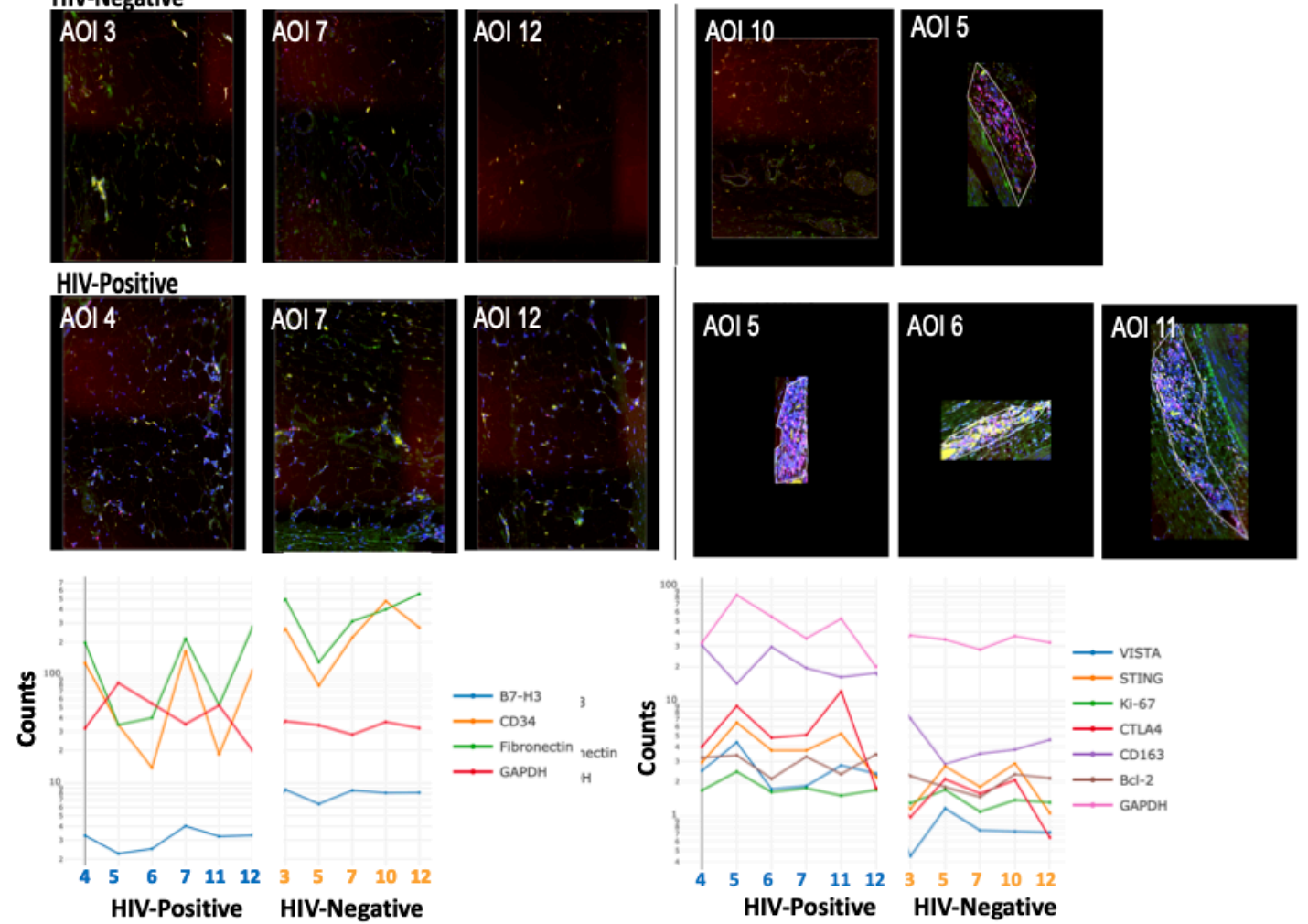

Figure 7. CD163, CTLA4, STING and VISTA are highly expressed in external AOls in the HIVpositive coronary plaque sample. Dendrogram with unsupervised clustering showing protein expression in HIV-positive and HIV-negative AOls (A). Differential gene expression of proteins in external AOls (adipose tissue and adventitia) by HIV-status (B). Trendlines and corresponding external images of the external AOIs $(C)$. Statistical analysis, t-test (green dashed line) $p<0.05$ and red dashed lines (fold change > 1). 


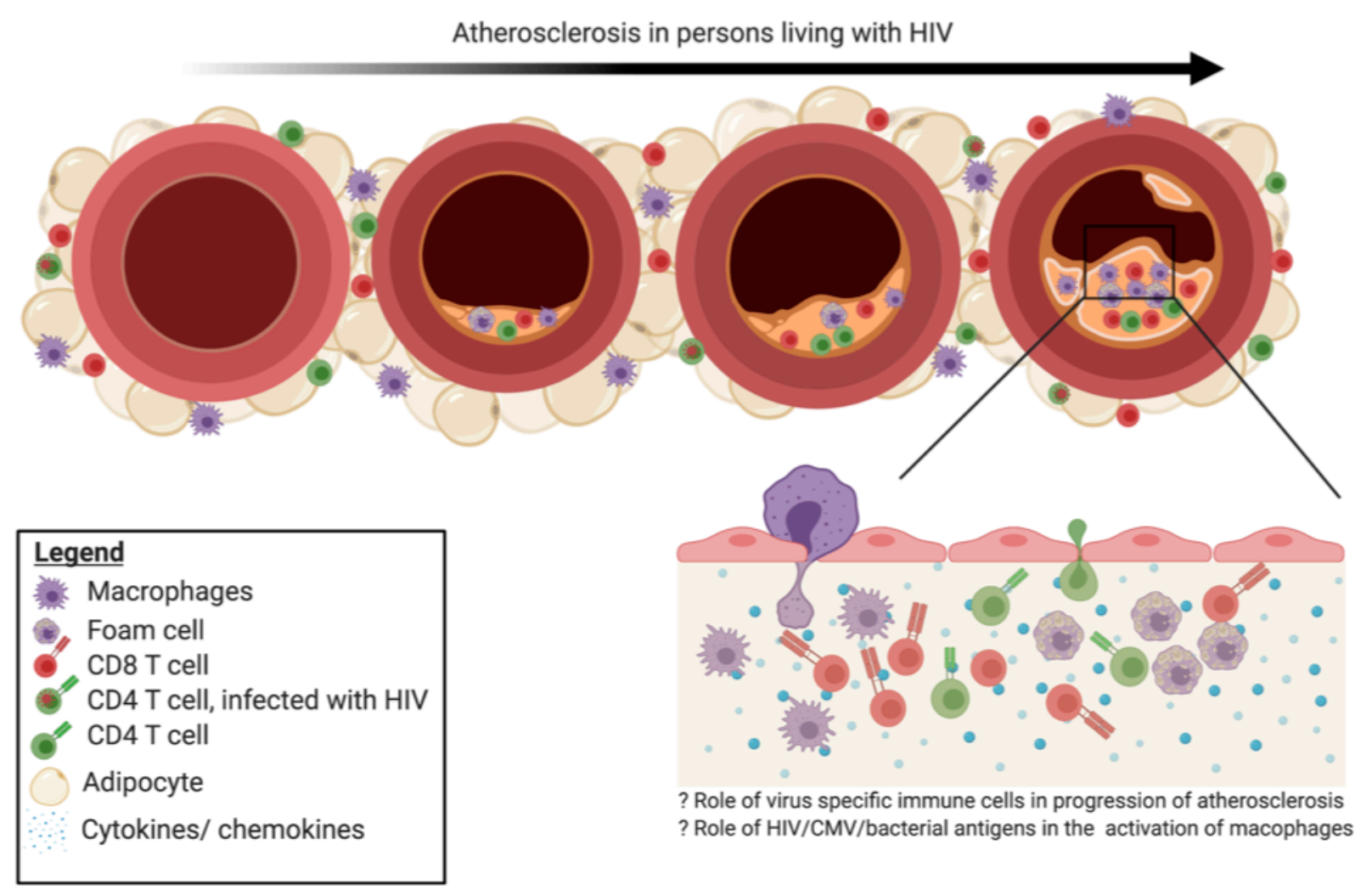

Figure 8. Proposed model. Virus-specific immune responses are important in the progression of atherosclerosis in PLWH. CD4 ${ }^{+}$T cells with HIV DNA have been detected in adipose tissue of PLWH. ${ }^{28,}$ 29, 44 CMV transcripts have also been reported in adipose tissue. ${ }^{45}$ In this paper, we show that PLWH had higher proportions of $\mathrm{CX} 3 \mathrm{CR} 1^{+} \mathrm{CD} 4^{+} \mathrm{T}$ cells in the perivascular adipose tissue and coronary plaque. $\mathrm{A}$ large proportion of CMV-specific CD4 ${ }^{+} \mathrm{T}$ cells are CX3CR1 ${ }^{+} .22,36,46,47$ This suggests that virus-specific immune cells are present within early atheromas. Higher expression of STING, CD25, Bcl-2, Ki-67, CD163 and GZMB suggests higher levels of activation in the samples from PLWH compared to the HIVnegative samples. Future studies looking at coronary plaques at different stages of atheroma will be evaluated to answer the question whether low level viral replication (HIV and CMV) can be detected in macrophages/ T cells in coronary plaques of PLWH on ART and whether the magnitude of viral transcripts correlate with the level of immune cell infiltration or activation. 